A N N A L E S Annales de Bretagne et des Pays de l'Ouest

\title{
Arnaud et Hoël, deux évêques du Mans au service de Guillaume le Conquérant
}

Yannick Hillion

\section{(2) OpenEdition}

\section{Journals}

Édition électronique

URL : http://journals.openedition.org/abpo/1467

DOI : $10.4000 /$ abpo. 1467

ISBN : 978-2-7535-1489-8

ISSN : 2108-6443

Éditeur

Presses universitaires de Rennes

Édition imprimée

Date de publication : 20 mars 2003

Pagination : 49-77

ISBN : 978-2-86847-811-5

ISSN : 0399-0826

\section{Référence électronique}

Yannick Hillion, « Arnaud et Hoël, deux évêques du Mans au service de Guillaume le Conquérant »,

Annales de Bretagne et des Pays de l'Ouest [En ligne], 110-1 | 2003, mis en ligne le 20 mars 2005,

consulté le 19 avril 2019. URL : http://journals.openedition.org/abpo/1467 ; DOI : 10.4000/abpo.1467

(C) Presses universitaires de Rennes 


\title{
Arnaud et Hoël, deux évêques du Mans au service de Guillaume le Conquérant
}

\author{
Yannick HILLION \\ Maître de conférences en histoire médiévale \\ CRBC-Université de Bretagne occidentale
}

En 1974, Bernard Guillemain attirait l'attention sur l'étude de l'épiscopat, non comme institution mais comme corps social " dont les membres sont insérés dans un monde dont ils dépendent et qu'à leur tour ils influencent ${ }^{1}$ ". Dans ce cadre et en complément des études récentes consacrées à l'Église du Mans ${ }^{2}$, il est intéressant d'étudier l'exemple des évêques Arnaud et Hoël. Au cours de la seconde moitié du XI ${ }^{\mathrm{e}}$ siècle, de 1065 à 1096, ces deux clercs normands d'origine modeste, issus de l'école cathédrale du Mans et dont la nomination et l'action relevèrent directement du duc roi Guillaume le Conquérant, occupèrent le siège épiscopal du Mans.

Qui voulait tenir le comté du Maine, devait tenir l'évêché. La mainmise par la famille de Bellême sur l'évêché du Mans durant la première moitié du $\mathrm{Xl}^{\mathrm{e}}$ siècle avait assez montré la faiblesse du pouvoir comtal des Hugonides dans le Maine, laissant ainsi porte ouverte à l'affrontement entre les ducs d'Anjou et de Normandie. Conquis en 1063, le comté du Maine restait pour le duc normand Guillaume une possession fragile, en situation de poste avancé, en marge de ses possessions héréditaires, exposée face à l'Anjou conquérant et contestée par les seigneurs manceaux. Il importait donc au duc Guillaume de placer des hommes sûrs à la tête de ce poste stratégique qu'était l'évêché. L'évêché du Mans faisait aussi partie de la province ecclésiastique de Tours dont l'archevêque relevait très probablement du roi de

1. Guillemain, Bernard, "Les origines des évêques en France aux XI" et XII siècles ", Miscellanea del centro di studi Medioevali, Milan, 1974, p. 375-407.

2. LEMESLE, Bruno, Les Évêques du Mans aux Xe et XII siècles. Modèle épiscopal, structure et fonctions du modèle à travers les Actus Pontificum Cenomannis in urbe degentium, mémoire de DEA dactylographié, Rennes, 1994; idem, « Le discours de l'Église aux temps grégoriens : évêques et laïcs dans le Maine aux XI ${ }^{\mathrm{e}}$ et XII ${ }^{\mathrm{e}}$ siècles, d'après les Actus Pontificum ", Annales de Bretagne et des Pays de l'Ouest, 1995, p. 17-32; Le Martre, Philippe, Le corpus carolingien du Mans : étude critique, thèse de $3^{\mathrm{e}}$ cycle dactylographiée, Paris XNanterre, 1980. 
France depuis le début du XI ${ }^{\mathrm{e}}$ siècle. Or depuis 1044, non seulement le roi avait laissé le comte d'Anjou s'emparer des honores tourangeaux de la maison de Blois mais il avait nommé archevêques Barthélemy, dès 1052-1053, puis en 1072-1073, Raoul I de Langeais dont les lignages étaient alliés à la maison angevine. D'autre part, l'évêché du Mans commandait en partie le statut de l'archevêché de Tours car c'est l'évêque du Mans, qui, dans le cadre de la province de Tours, devait veiller à chaque vacance de siège sur le sort de l'église archiépiscopale et procéder au sacre de l'archevêque.

Le duc Guillaume, qui fut toujours maître de ses évêchés normands, entendait bien le rester en territoire conquis. Ses choix, souvent judicieux pour les évêques normands, furent particulièrement adaptés et efficaces pour le siège manceau. Après avoir accompagné l'un et l'autre le nouvel essor de l'école cathédrale de la cité, Arnaud dut à son origine, Hoël à son appartenance à la chapelle du nouveau roi d'Angleterre, d'accéder à l'épiscopat. De l'action politique d'Arnaud dans son ensemble, il nous a paru utile de retenir la mise en place à la tête de l'abbaye mancelle de la Couture, d'un homme issu des réseaux normands fidèles et appartenant à cet Avranchin qui avait déjà été l'objet de toutes les sollicitudes du duc-roi. La mort de Guillaume le Conquérant en 1087 laissa l'évêque Hoël seul et en première ligne dans un comté du Maine peu à peu laissé pour compte par son successeur normand en titre, Robert Courte Heuse. La reconquête, par un des héritiers légitimes du comté, laissé vacant de fait, conduira l'évêque, désormais libéré de sa mission politique, à participer à l'action réformatrice de l'Église vivement relancée dans toute la région par le pape Urbain II.

Arnaud et son parent Hoël furent avant tout des "homines novi » dont il est intéressant d'étudier la place dans le monde anglo-normand, alors en pleine ascension, et dans le monde de l'Église, alors en pleine réforme.

\section{La formation d'Arnaud et d'Hoël}

\section{Les écoles monastiques du Mans}

$\mathrm{Au} \mathrm{XI}{ }^{\mathrm{e}}$ siècle, Le Mans offre dans les principaux monastères bénédictins de la cité plusieurs écoles monastiques. L'abbaye de la Couture qui fut restaurée par l'abbé Gauzbert de Saint-Julien de Tours ${ }^{3}$ témoigne de relations avec la région ligérienne dont l'abbaye de Fleury constituait alors un des principaux foyers d'études monastiques de la région et de la France ${ }^{4}$. Un moine lettré de l'abbaye de Micy, près d'Orléans, Létald ${ }^{5}$, dont l'origine

3. OuRY, Guy-Marie, « La reconstruction monastique dans l'Ouest : L'abbé Gauzbert de Saint-Julien de Tours (vers 990-1007) ", Revue Mabillon, 1964, p. 69-124.

4. Riche, Pierre, Écoles et Enseignement dans le haut Moyen Âge, Paris, 1999, p. 144. Ingelbaud qui succéda comme premier abbé en titre de la Couture après la mort du réformateur, en 1007, est lui-même un ancien moine de Saint-Julien de Tours.

5. VulliEz, Charles, Des Écoles de l'Orléanais à l'université d'Orléans (XIe-début XIVe siècle), thèse de doctorat d'État, Paris X, 1994. Voir : " Les hommes dans le cloître : esquisse d'une prosopographie monastique », p. 162-163. L'auteur l'identifie à Létald II (moine sous 
mancelle est incertaine, vint à la suite d'une conspiration contre son abbé Robert se réfugier au Mans auprès de l'évêque Avesgaud ${ }^{6}$. Il lui dédicaça une vita sancti Juliani, du nom du premier évêque du Mans ${ }^{7}$. L'abbaye de la Couture où il se retira bénéficia de son rayonnement ${ }^{8}$.

La charte de fondation du prieuré de Solesmes, en 1010 laisse entrevoir, aux côtés de l'abbé de La Couture Ingelbaud, sans d'ailleurs préciser leurs liens avec l'abbaye, la présence de témoins comme Robert grammaticus ou Guérin, hec dictantis et scribentis ${ }^{9}$. À la fin du XI ${ }^{\mathrm{e}}$ siècle, Johel, avant de devenir abbé de la Couture, y fait probablement ses études : on lui doit un récit de miracles opérés à Angers par saint Nicolas, évêque de Myra en Lycie, et qu'il dédia à l'abbé Noël de Saint-Nicolas d'Angers ${ }^{10}$. Au XII ${ }^{\mathrm{e}}$ siècle, l'abbaye continue à entretenir une école où sont instruits enfants et jeunes gens qui lui sont confiés. Un acte d'environ 1112, du temps de l'abbatiat d'Odon de Bures, compte parmi ses témoins un certain nombre de jeunes et d'enfants dont on peut penser qu'ils sont élevés et éduqués à l'abbaye. Cette liste suivie de témoins stipulés comme laïcs de laicis, laisse supposer par opposition que ces jeunes sont bien membres du monastère ou futurs moines ${ }^{11}$.

Nous avons peu de renseignements sur l'existence d'une école à l'abbaye de Saint-Calais : à la fin du XI ${ }^{\mathrm{e}}$ siècle toutefois, le normand Guillaume, futur évêque de Durham, était venu rejoindre à Saint-Calais son père, moine, et y aurait poursuivi des études en lettres profanes et sacrées ${ }^{12}$. L'abbaye de Saint-Vincent possédait une, sinon deux écoles. Du temps d'Arnaud, un acte du cartulaire de Saint-Vincent évoque un certain Robert le Clerc, neveu de Foulque qui, à la veille d'un long voyage, (vers Rome ou Jérusalem) remet ses biens en gage pour obtenir de l'argent à l'abbé de Saint-Vincent, Hoël ${ }^{13}$. Il remet entre les mains de l'abbé et des moines tout ce qu'il tenait d'eux, notamment l'église paroissiale de Saint-Vincent ainsi que l'école et les revenus de sa prébende provenant des moulins. Il dépose sur l'autel les revenus de l'église Sainte-Marie, de l'école et des moulins en échange de sa partici-

l'abbé Annon, post 940) et le distingue ainsi d'un Létald I, abbé de Micy, au début du X ${ }^{\mathrm{e}}$ siècle.

6. Avesgaud devient évêque en 997.

7. Migne, Jacques-Paul, Patrologie Latine, Paris, 1844-1864 [en abrégé Patrologie latine] : t. 137 , col. 751 .

8. Dans RichE, Pierre, op. cit., p. 145, note 18, Létald est crédité d'un nombre relativement important d'écrits; outre le Liber Miraculorum sancti Maximini, lui est attribué un poème de deux cents hexamètres sur l'aventure d'un anglo-saxon avalé par une baleine.

9. Bénédictins de Solesmes, Cartulaire des abbayes Saint-Pierre de la Couture et de SaintPierre de Solesmes, Le Mans, 1881 [en abrégé Cartulaire de la Couture], acte VIII.

10. Religieux Bénédictins de la Congrégation de Saint Maur, Histoire littéraire de la France, Paris, 1868, t. VIII, p. 444-445.

11. Cartulaire de la Couture, Acte XXXIX, p. 47.

12. DurhaM, Siméon de, Historia ecclesiae dunhelmensis, Thomas ARNOLD (ed.), London, 1882-1885, t. I, p. 119 : Guillaume est qualifié de " ecclesiasticis et secularibus litteris nobiliter eruditus... in divinis et humanis rebus multum industrius ".

13. Charles, Léopold et Menjot d'Elbenne, Victe Samuel, Cartulaire de l'abbaye SaintVincent du Mans (572-1184), Mamers/Le Mans, 1886-1913, [en abrégé Cartulaire de SaintVincent], 32 et Gallia Christiana, t. XIV, col. 456. 
pation aux prières et à la société des moines ${ }^{14}$. L'église Sainte-Marie est l'église paroissiale du bourg de Saint-Vincent, située près du monastère (juxta $S$. Vincentium); cette église dédiée à la Vierge est bien sûr distincte et séparée de celle de l'abbaye ${ }^{15}$. Quelle est cette école attachée semble-t-il, à l'église Sainte-Marie de la paroisse de Saint-Vincent? Un certain nombre de monastères établissaient deux écoles, l'une intérieure destinée aux oblats, l'autre extérieure pour les clercs étrangers. L'école extérieure était parfois attribuée au desservant de l'église paroissiale proche du monastère ${ }^{16}$. Les monastères ayant la charge de veiller à leurs écoles paroissiales se devaient de pourvoir au recrutement et à l'entretien du personnel. Robert le Clerc est peut-être une sorte de maître d'école qui fut recruté par l'abbé pour sa paroisse, sorte de représentant d'un préceptorat individuel. Certains clercs pouvaient posséder de modestes biens et y tenir école pour y enseigner à la population du bourg. Nous savons, par ailleurs, qu'à la fin du Xie siècle, un certain Odon donna aux moines un terrain et un jardin à la condition qu'ils instruisent son fils du psautier ${ }^{17}$, c'est-à-dire qu'ils lui apprennent à lire à l'aide de ce livre de lecture élémentaire partout employé à l'époque ${ }^{18}$. Odon demande ainsi aux moines d'assurer un enseignement simple pour son fils qui semble bien destiné à la vie séculière. Sera-t-il éduqué au monastère même ou plutôt, dans son cas, dans cette école externe? C'est, en tout cas à l'abbaye de saint-Vincent que Robert Grammaticus, oncle du futur évêque Arnaud et membre éminent de l'école épiscopale, choisira de donner non seulement des terres et des vignes, mais aussi des livres précieux qu'il possédait en propre : "Robertus grammaticus dedit Sancto Vincentio IVor arpennos vinearum. Preterea dedit huic sanctuario Vincentii et Laurentii Robertus grammaticus de suis facultatibus hec: unam bibliothecam, unam per partes divisam $^{19}$, canonicale ${ }^{20}$, unum Smaragdum ${ }^{21}$, passionale ${ }^{22}$ et duos agri-

14. Cartulaire de Saint-Vincent, 32.

15. Cartulaire de Saint-Vincent, 83 : au début du XII ${ }^{\mathrm{e}}$ siècle, un prêtre de cette paroisse est nommément désigné : "Godefrido presbitero Sancte Marie. "

16. BERLIERE, Ursmer, "Les écoles claustrales au Moyen Âge ", Bulletin de la classe des lettres de l'Académie royale de Belgique 1921, p. 564, en cite un bon nombre.

17. Cartulaire de Saint-Vincent, 577.

18. Riche, Pierre, op. cit., p. 223.

19. Il s'agit de la Bible divisée vraisemblablement en ses diverses parties ou livres. Il peut s'agir du volume ou de l'ensemble des livres saints. RichE, Pierre et LoBrichon, Guy, Le Moyen Âge et la Bible, Paris, 1984, p. 14-15 : "Bibliotheca désigne souvent un volume (codex) contenant les divers livres bibliques, conçu sous son aspect matériel. "

20. Canonicale : codex canonum, ut conjecto, dans Du CANGE, Charles, Glossarium, II, 99 qui cite précisément cet acte en exemple, avec pour référence MABILLon, Jean, Annal Benedict..., t. 4, p. 441.

21. Il peut s'agir d'un traité de Smaragde, abbé vers 805-810 du monastère de Saint-Mihiel sur Meuse. De culture wisigothique, il rédigea pour ses élèves la première grammaire latine née sur le sol de l'ancienne Gaule depuis trois siècles. Attestée par une vingtaine de manuscrits surtout de la deuxième moitié du $\mathrm{x}^{\mathrm{e}}$ siècle elle est utilisée très tôt, notamment dans les monastères armoricains où on y retrouve des gloses en vieux breton. Il a laissé d'autres écrits dont le Diadema monachorum, guide de la vie monastique largement répandu.

22. Passionalis, Passionarium, liber continens passiones Sanctorum, dans Du CANGE, Glossarium, VI, 198. 
pennos vinearum et dimidium. "C'est un don considérable puisqu'il s'agit, en dehors des donations foncières, elles-mêmes importantes, de la Bible et de livres saints qu'il possédait et dont il devait se servir pour son usage propre ou pour son enseignement. Selon les Actus des évêques du Mans, Robert le Grammairien fut un homme respecté pour son savoir, sa connaissance des livres sacrés mais aussi pour sa vie pieuse et toute dévouée non à l'école de Saint-Vincent mais à l'essor de l'école de la cathédrale ${ }^{23}$.

\section{Arnaud, Hoël et l'école épiscopale du Mans}

Les origines et la formation d'Arnaud et Hoël ne les rattachent cependant pas aux écoles monastiques du Mans, mais plutôt à son école épiscopale. Arnaud, fils de prêtre, neveu de ce Robert le Grammairien, est né vraisemblablement vers $1011^{24}$, en Avranchin, à Saint-Maur-des-Bois, à une vingtaine de kilomètres au nord-est d'Avranches, non loin de la forêt de Saint-Sever ${ }^{25}$. On ne retrouve sa trace que sous l'épiscopat de l'évêque du Mans Gervais de Château du Loir (vers 1035-1055), en tant que grammaticus et membre du chapitre de l'église du Mans ${ }^{26}$ et de façon plus précise, en 1037 où il apparaît alors comme diacre et grammaticus dans un acte du même évêque Gervais, en faveur de la Trinité de Vendôme ${ }^{27}$. Arnaud fut très tôt éduqué par son oncle Robert le Grammairien, au sein du chapitre cathédral dont Robert dirigeait l'école. Il partagea la vie studieuse de Robert et suivit son exemple ${ }^{28}$. À vingt-six ans, Arnaud est alors connu comme grammaticus, quoique simple diacre. Il ne dut recueillir la succession de son oncle à la tête de l'école du Mans qu'après sa mort. Sous l'épiscopat des évêques Gervais et Vulgrin, il tient alors le regimen scolarum de l'école épiscopale du Mans et le 13 février 1056, on note sa présence à Chalon sur Saône lors d'un concile présidé par Hildebrand, aux côtés de l'archevêque de Tours et de son évêque Vulgrin qu'il accompagne comme son scholasticus ${ }^{29}$.

L'école épiscopale du Mans fut créée au IX siècle, comme le stipulait l'Admonitio generalis dont le concile de 816 renforçait l'obligation. Celle-ci existait sans doute ou fut alors créée à l'arrivée d'Aldric « fidèle d'entre les fidèles " de Louis le Pieux et que l'empereur nomme à l'évêché du Mans,

23. Actus Pontificum Cenomannis in urbe degentium, Busson, Abbé Gustave et LEDRU, Abbé Ambroise (éd.), Archives historiques du Maine, t. 2, Le Mans, 1901 (ou Actus), p. 381.

24. Actus, p. 382. La mort d'Arnaud, chargé d'infirmités à près de 70 ans, en novembre 1081 , situe sa naissance vers 1011 .

25. Actus, p. 374-375 et Bibliothèque nationale de France, collection Baluze, $\mathrm{n}^{\circ}$ 77, «Ex chartulartio Cenomanensi Majoris monasterii Turonensis ", $\mathrm{n}^{\circ}$ 82, p. 21.

26. Chartularium insignis ecclesie Cenomanensis quod dicitur Liber Albus capituli, E. Monnoyer, 1869 (ou Liber Albus), Acte 179.

27. Metals, Charles, Cartulaire de la Trinité de Vendôme, Paris, 1893-1904, Acte 14, p. 32. La donation de Gervais est confirmée en 1037.

28. Actus, p. 375.

29. Ibidem. Gian-Domenico MANSI, Sacrorum conciliorum nova et amplissima collectio, Florence et Venise 1759-1798, t. XIX, 843. 
en $832^{30}$. Une étude plus approfondie des documents fournirait peut-être quelques preuves de ce que devient cette école au cours des $\mathrm{IX}^{\mathrm{e}}$ et $\mathrm{X}^{\mathrm{e}}$ siècles. En tout état de cause, il est vraisemblable qu'il n'y a pas eu de véritable interruption de l'école ${ }^{31}$. Comme le souligne Émile Lesne, "la nécessité obligeait les églises, comme les monastères d'ailleurs, à donner un enseignement même rudimentaire à leurs jeunes recrues et les écoles créées au début du $\mathrm{IX}^{\mathrm{e}}$ siècle se sont donc maintenues même si quelques indices seulement de cette permanence apparaissent au cours des $\mathrm{IX}^{\mathrm{e}}$ et $\mathrm{X}^{\mathrm{e}}$ siècles ". Le nom des maîtres ne réapparaît souvent qu'au XI ${ }^{\mathrm{e}}$ siècle.

L'école du Mans elle-même réapparaît dans les textes en $1010^{32}$, sous l'épiscopat d'Avesgaud (995-1035) quand Robert Grammaticus contribue à la sortir de son délabrement et la restaure ${ }^{33}$. Cette " restauration " de l'école épiscopale implique une remise en activité, non une fondation proprement dite. Il est d'ailleurs rare que des documents fassent mention de la " fondation " d'une école. À la fin du $\mathrm{xI}^{\mathrm{e}}$ siècle, au dire de Guibert de Nogent, on ne connaissait dans les petites localités aucun grammaticus et dans les villes à peine quelques-uns et de science très courte ${ }^{34}$. C'est dire le privilège de la cité du Mans de compter ce grammaticus dès 1010. On retrouve Robert trente ans après au moment de la restauration de l'abbaye de Saint-Vincent par l'évêque du Mans Gervais, vers 1035-1055 ${ }^{35}$. Robert y apparaît encore comme grammairien. L'importante donation qu'il fait alors à Saint Vincent et notamment celle de ses propres livres sans doute devenus inutiles pour lui, est peut-être un legs pieux accompli au seuil de la mort ${ }^{36}$.

30. LE MaITRE, Philippe, "L'œuvre d'Aldric du Mans et sa signification (832-857) ", Francia, vol. 8, 1980, p. 48. Venu du chapitre de Metz, haut-lieu de la réforme religieuse carolingienne, Aldric apporte avec lui ce souci de formation. "En résumé, il ne semble pas que l'instruction au Mans, sous Aldric, ait dépassé le niveau minimal recommandé par l'Admonitio Generalis : Psaumes, notes, chant, comput grammaire. Seules les connaissances liturgiques et les techniques liées à l'existence d'un scriptorium actif, éléments de droit et de diplomatique semblent avoir été davantage développées. "

31. LESNE, Émile, Histoire de la propriété ecclésiastique en France, Lille, 1940, t. V, p. 441 : " Il est vraisemblable qu'une chaîne ininterrompue de maîtres dont nous ne connaissons pour le $\mathrm{IX}^{\mathrm{e}}$ et le $\mathrm{X}^{\mathrm{e}}$ siècle que quelques anneaux a relié semble-t-il les écolâtres des $\mathrm{XI}^{\mathrm{e}}$ et XII ${ }^{\mathrm{e}}$ siècles aux maîtres contemporains d'Alcuin, de Raban Maur et d'Heric d'Auxerre. "

32. Cartulaire de la Couture, VIII et IX.

33. Actus, p. 375.

34. Gubert de Nogent, Autobiographie, Labande, Edmond-René (éd.), Les classiques de l'histoire de France au Moyen Âge, 34, Paris, 1981, p. 26.

35. Cartulaire de Saint-Vincent, 6. Toutefois, le 31 mai 1040, un certain Ermenulfus apparait avec le titre de scolasticus souscrivant comme représentant de l'église du Mans une charte de Thierry, évêque de Chartres. Metals, Charles, Cartulaire de la Trinité de Vendôme : Acte 39, p. 85. Cet acte étant un faux fait, par conséquent, douter de l'existence de cet Ermenulfus. L'Histoire Littéraire de la France [op. cit., supra, n. 10], t. VII, p. 573, mentionne cependant ce personnage à propos de l'évêque Gervais qui « élevé à la cathédrale où il apprit les arts libéraux trouva à la tête de cette école Ermenulphe qui la dirigea au moins jusqu'en 1040 ".

36. Cf. supra, notes 19 à 23. Il n'est guère possible de le confondre avec Robert le Clerc, détenteur de l'école paroissiale de Saint-Vincent. Non qu'il puisse, même à un âge avancé, tenter un tel voyage, mais du fait que, dans cet acte, Robert le Clerc qui se qualifie lui-même de " neveu de Foulque ", ne signale pas de parenté avec l'évêque Arnaud, alors présent. 
On ne sait pas où Robert le Grammairien reçut sa formation. Il a pu étudier à Reims où la famille de l'évêque Avesgaud, les Bellême, avaient des liens; Avesgaud était aussi lié à l'évêque Fulbert de Chartres, mais rien n'indique que Robert ait été formé auprès de Fulbert ${ }^{37}$. L'école d'Angers, célèbre alors pour sa formation, aurait pu aussi recevoir ce grammairien ${ }^{38}$. Une dernière tradition propose Avranches, bien qu'il semble difficile d'imaginer l'existence d'une école dans ce diocèse alors en pleine reconstruction ${ }^{39}$. Cependant, des liens familiaux pourraient rattacher Robert à l'Avranchin dont son neveu Arnaud était originaire. En cette fin du $\mathrm{X}^{\mathrm{e}}$ siècle surtout, d'étroites relations autant religieuses que politiques unissent le Maine à l'Avranchin ${ }^{40}$. Ces relations pouvant être aussi culturelles, l'hypothèse d'une école à Avranches n'est pas à écarter.

Si l'épiscopat d'Avesgaud marque les commencements de l'école du Mans, l'évêque Gervais de Château-du-Loir semble aussi avoir soutenu l'essor de cet enseignement. "Dernier grand représentant de la tradition carolingienne ${ }^{41}$ ", Gervais a sans doute protégé les hommes de savoir et notamment au Mans, les restaurateurs de l'école épiscopale. La présence constante de Robert le Grammairien auprès de l'évêque vient étayer cette thèse. Robert est à ses côtés lors de la restauration de l'abbaye de SaintVincent et contribue à en enrichir la bibliothèque ${ }^{42}$. Plus tard, le jeune diacre Arnaud figure avec Gervais dans la donation à la Trinité de Vendôme

37. BEHRENDS, Frederick, The letters and Poems of Fulbert of Chartres, Londres, 1974, Lettre 87, p. 154-156. Dans sa lutte contre Herbert comte du Maine, Avesgaud signe avec Fulbert une lettre de demande d'aide à l'archevêque de Reims.

38. Telles sont aussi les hypothèses de Foulon, Jean-Hervé, La Réforme de l'Église dans la France de l'Ouest de la fin du XI siècle au milieu du XII siècle, thèse de doctorat dactylographiée, Paris 1998, p. 72.

39. L'évêque Norgodus (Norgot) restaure le siège d'Avranches en 990. Il est le premier évêque connu depuis Walbertus présent au synode de Pîtres en 862.t, GiBSON, Margaret, Lanfranc of Bec, Oxford 1978, p. 19, estime que les conditions d'un tel enseignement étaient déjà difficiles une génération plus tard, au moment de l'arrivée de Lanfranc à Avranches.

40. L'abbaye du Mont-Saint-Michel reconstitue deux prieurés, celui de Saint-Victeur autour de la ville du Mans et celui de l'Abbayette aux confins de l'Avranchin, du Maine et du pays de Fougères, grâce à la générosité des comtes du Maine et de leurs alliés manceaux, en relation avec les maisons de Rennes et de Blois-Chartres. Les mêmes ont déjà contribué à la restauration de l'abbaye du Mont-Saint-Michel en 966. KEATs-RoHAN, Katharine S. B., " Une charte de l'abbé Mayeul de Cluny et la réforme du Mont-SaintMichel ", La Normandie vers l'an mil, Rouen Société de l'Histoire de Normandie, 2000, p. 159-167; idem, " Bibliothèque municipale d'Avranches, 210 : Cartulary of Mont-SaintMichel " Anglo-Norman Studies XXI (1999), p. 95-112; id., "Two studies in North French Prosopography I - Ivo fitz Fulcoin, the counts of Maine, the lords of Bellême and the foundation of L'Abbayette ", Journal of Medieval History, 20, 1994, p. 3-37.

41. Bur, Michel, " La formation du comté de Champagne, v. 950-v. 1150 ", Mémoires des Annales de l'Est, Nancy, 1977, p. 208, note 50. Un magnifique Évangéliaire du Ix ${ }^{\mathrm{e}}$ siècle dit Évangélaire de Gervais compte parmi les plus beaux manuscrits carolingiens. On y remarque, notamment, les quatre évangélistes dessinés en pleine page et aux folios 19 et 53, la mention, en écriture onciale : "Hunc codicem ornavit Gervasius, auro, gemmis et emblematis, tunc Cenomannensis postea Remensis episcopus. "

42. Cf. supra, notes 19-23. 
et comme grammaticus au sein du Chapitre du Mans ${ }^{43}$. Arnaud tient, à partir de l'épiscopat de Gervais, le regimen scholarum de cette église ${ }^{44}$.

Une génération après celle de Robert, au milieu du XI ${ }^{\mathrm{e}}$ siècle, Avranches est profondément marqué par le passage de Lanfranc. Parti d'Italie vers 1030, Lanfranc arrive à Avranches vers 1040. Il n'est pas certain qu'il y ait enseigné, quoiqu'il y ait séjourné, à coup sûr, quelques temps ${ }^{45}$. Une certaine tradition rapporte qu'Arnaud, de la même génération que Lanfranc, l'aurait rencontré et profité de ses leçons, mais aucun témoignage d'Arnaud, qui n'aurait pas manqué de relater une relation aussi prestigieuse, ne vient soutenir cette hypothèse. Pourtant Lanfranc a pu avoir des contacts avec les clercs du Mans, voire avec l'évêque Gervais : lorsque l'hérésie de Bérenger éclate en 1049 et provoque ouvertement Lanfranc, Gervais, défenseur de l'orthodoxie romaine, correspondant régulier de la papauté, prend parti contre Bérenger ${ }^{46}$. Lanfranc aurait, à cette occasion, séjourné au Mans et y aurait corrigé quelques manuscrits. Il existe encore à la Bibliothèque du Mans un manuscrit du $\mathrm{xI}^{\mathrm{e}}$ siècle de l'Hexaemeron de saint Ambroise écrit sur parchemin sur lequel, en bas du folio 141, on peut lire en lettres capitales : "Lanf(rancus). Huc usque correxi ${ }^{47}$."

On ne sait pas si ces relations hypothétiques entre l'Église du Mans et Lanfranc influencèrent des relations postérieures avec l'abbaye du Bec dont Lanfranc devint le prieur vers 1045. Ces relations existèrent cependant mais paraissent avoir été ténues : certes, Arnaud, devenu évêque du Mans, assiste en 1077, à la dédicace de l'église du Bec en présence de Lanfranc, alors archevêque de Canterbury et de quelques évêques, mais, seul " horsain " parmi tous les évêques normands, sa présence toute politique, ne fait que témoigner, s'il en était besoin, de son appartenance au cercle des familiers du roi Guillaume ${ }^{48}$. Plus concrètement, un moine de

\section{Cf. supra, note 26 .}

44. Cf. supra, note 29. Gervais semble avoir suivi la même politique à Reims, lorsqu'il rencontre Bruno le futur fondateur de l'ordre des Chartreux. Bruno, arrivé de Cologne fut d'abord chanoine de la cathédrale quand Gervais lui confia la direction de son école. GUIBERT DE NOGENT, Autobiographie..., op. cit., p. 62.

45. Riche, Pierre, "La vie scolaire et la pédagogie au Bec au temps de Lanfranc et de Saint Anselme ", Les mutations socioculturelles au tournant des XI ${ }^{e}$-XII siècles, Études Anselmiennes, IV e session, Le Bec-hellouin, 1982 p. 214. GiBson, Margaret, op. cit., p. 19, estime qu'un enseignement de Lanfranc à Avranches est improbable.

46. Du Boulay, César Égasse, Historia Universitatis Parisiensis, Frankfurt, 1966, t. I, p. 424.

47. Manuscrits des Bibliothèques publiques de France, t. XX, p. 30, n ${ }^{\circ} 15: S$ Ambrosii Mediolanensis episcopi opuscula. Ce manuscrit est en parchemin, de 142 feuillets et relié en basane. «Les initiales de ces différents traités sont ornées d'animaux fantastiques au trait sur fond ordinairement rouge et quelquefois vert. Les corrections qu'on remarque en plusieurs endroits du texte ont été attribuées à Lanfranc ". L'Histoire littéraire de la France, [op. cit., supra, n. 10], t. VIII, p. 287, précise : " On a dit que Lanfranc, nonobstant ses grandes occupations, s'appliquait à corriger les exemplaires de la Bible, des ouvrages des Pères et autres livres ecclésiastiques. On en voit encore aujourd'hui quelques uns corrigés de sa main, à Saint-Vincent du Mans, l'Hexameron de Saint Ambroise, son apologie de David, le traité des sacrements attribué au même père et à Saint Martin de Séez les Conférences de Jean Cassien. "

48. Patrologie Latine, t. 150, col. 646, Chronicon Beccense. 
l'abbaye de la Couture du Mans, Avesgot, avait écrit à Anselme, alors moine au Bec, pour lui demander d'instruire son neveu, déjà jeune homme et " dont il s'occupe en tout ". Dans cette lettre, Avesgot y déplore la modestie d'Anselme alors que « la réputation de Lanfranc et de Guitmond vole à travers le monde ${ }^{49}$ ". Il est pourtant le seul en qui il ait confiance ${ }^{50}$. Mais Anselme refusera, ne voulant pas enseigner la grammaire ${ }^{51}$.

Le successeur d'Arnaud à l'évêché du Mans est son propre disciple Hoël. Si Arnaud et Hoël ne sont pas parents de sang, ils sont en tout cas très proches ${ }^{52}$. Véritablement " nourri " c'est-à-dire formé et éduqué depuis l'enfance et l'adolescence à l'école du Mans ${ }^{53}$, Hoël symbolise bien la continuité de cette " famille cléricale " qui depuis le début du XI ${ }^{\mathrm{e}}$ siècle, contribue à l'essor de l'école épiscopale. C'est tout naturellement en pur produit de cette école qu'Hoël prend place au sein du chapitre comme chanoine, puis comme doyen ${ }^{54}$. Le cartulaire de Saint-Vincent notamment, illustre clairement la familiarité quasi quotidienne d'Arnaud et Hoël, tout au long des actes de la pratique épiscopale, à travers le diocèse ou jusqu'en Anjou ${ }^{55}$.

\section{Arnaud à Paris, Hoël, clerc de la chapelle du roi d'Angleterre}

La formation d'Arnaud et Hoël s'est poursuivie après l'enseignement dispensé par l'école du Mans. Une génération après celle de Robert le Grammairien, la vie intellectuelle se transforme peu à peu et les nouveaux centres urbains attirent les jeunes clercs par leur innovation. Les maîtres et les étudiants deviennent volontiers itinérants. Quitter l'école pour chercher un autre maître dans une autre ville était une tentation fréquente chez les jeunes clercs. Paris, en particulier, commence à devenir un centre dont le rayonnement attire ${ }^{56}$.

49. Patrologie Latine, t. 143 col. 1431. Lanfranc et Guitmond furent très impliqués dans la controverse eucharistique soulevée par Bérenger de Tours. Guitmond d'Aversa fut un moine très lettré de La-Croix-Saint-Leufroy (diocèse d'Évreux). Il fut l'élève de Lanfranc vers 1060 et s'est rendu célèbre à l'occasion de cette affaire. Sa réputation dépassa de son vivant celle d'Anselme. En 1088, le pape Urbain II le fit évêque d'Aversa, en Italie du sud. Il meurt avant 1097. (ORDERIC VITAL, The ecclesiastical history of Orderic Vitalis, ChiBnall, Marjorie (éd.), Oxford, 1969-1980, vol. II, livre IV, p. 270-280).

50. Patrologie latine, t. 143, col. 1431, lettre où Avesgot, mentionné comme moine de la Couture, s'adresse à Anselme sans lui attribuer de titre. Si ce n'est pas une faute de sa part, cela indiquerait qu'Anselme est encore simple moine. Il devient prieur du Bec en 1063.

51. Patrologie Latine, t. 158, col. 1082, réponse d'Anselme à Avesgot dans Epistola $X V I$. Anselme n'a guère de goût pour l'enseignement élémentaire et ses préoccupations intellectuelles (et spirituelles) sont d'un autre ordre.

52. Gallia Christiana, t. XIV, col. 375.

53. Actus, p. 382.

54. Gallia Christiana, t. XIV, col 375 et Actus p. 382.

55. Cartulaire de Saint-Vincent, 23, 40, 28, 53, 29, 472, 175, 65, 188. Paul MarchegaY, Archives d'Anjou, t. III, Cartularium monasterii Beatae Mariae Andegavensis, Angers, 1854, p. 222, Acte 365 .

56. LESNE, Émile, op. cit., t. V, p. 198 : « Au cours du XI siècle, Paris devient manifestement l'un des rendez-vous où se pressent les jeunes clercs avides de science " et RicHE, Pierre, op. cit., p. 203. 
Une tradition, contestable il est vrai, rapporte qu'Arnaud se serait trouvé à Paris en compagnie d'un certain nombre de clercs lettrés comme lui, plus ou moins connus à un titre ou à un autre et venus de différents horizons. Un texte isolé et donc sujet à caution mentionne que, vers 10351036, le grammairien Arnaud (il a alors environ vingt-cinq ans), connu sous le nom d'Arnaldus Abracinsis, aurait ainsi côtoyé Bérenger de Tours qui enseignait là la dialectique en compagnie de Lanfranc lui-même ${ }^{57}$. Il aurait également rencontré d'autres écolâtres et grammairiens, Albert Pexiacensis seu Pisciacensis ${ }^{58}$, un compatriote, Bernard du Mans, un allemand Bregaudus Teutonicus... Parmi cette compagnie, un Haymon l'Anglais, Haymo Anglus, avait préféré quitter l'Angleterre troublée par les guerres, pour se consacrer plus tranquillement aux lettres, enseigner la théologie et finalement devenir moine à Saint-Denis ${ }^{59}$. Tout cela n'est pas invraisemblable : le séjour parisien du grammairien Arnaud dans le milieu de ces clercs de la première moitié du $\mathrm{XI}^{\mathrm{e}}$ siècle est possible, beaucoup d'élèves pouvant ainsi quitter leur école avec l'autorisation de l'évêque ou de l'abbé pour compléter leurs études.

Nous avons par contre plus de certitude en ce qui concerne la suite de la formation d'Hoël. Il dut sans doute à sa réputation de chanoine lettré d'entrer dans la chapelle du roi Guillaume où il put se perfectionner au contact de l'administration anglaise et surtout fréquenter et se faire connaître des milieux proches du Prince. Les déplacements étaient particulièrement aisés et fréquents entre le Maine, la Normandie et l'Angleterre. Le recrutement d'Hoël au sein de la chapelle du roi d'Angleterre ne doit certainement rien au hasard. Ancien élève et proche du " normand " Arnaud, c'est en tant que doyen du chapitre cathédral qu'Hoël avait déjà rencontré le roi Guillaume dans sa propre camera, l'année de la trêve du château de Vaux en $1078^{60}$.

Après la mort de l'évêque Arnaud, le 29 novembre 1081, il était évidemment important pour le roi Guillaume d'assurer cette succession et de trouver un autre homme de confiance pour le remplacer à la tête de l'évêché d'un comté toujours contesté aux Normands. C'est précisément au sein de sa propre chapelle que le roi Guillaume trouvera son homme. Orderic Vital nous a laissé un récit pittoresque décrivant la façon dont le roi aurait suivi le conseil de son chapelain Samson de Bayeux et désigné

57. TRITHEMII SPANHEIMENSIS, Johannis, Annalium Hirsaugiensium, 1690, « claruit his etiam temporibus Lanfrancus... qui scholis apud Parisienses, multo tempore praesidens, magnam eruditionis suae laudem et gloriam acquisivit".

58. Albert de Poissy.

59. Du Boulay, César Égasse, Historia Universitatis, t. I, p. 404. Les auteurs de l'Histoire Littéraire de la France [op. cit., supra, n. 10], t. VIII, p. 261, ne croient pas au séjour de Lanfranc à Paris : "Étant arrivé à Avranches avec une bande d'étudiants tous gens de mérite qui s'étaient attachés à lui, il y enseigna quelque temps et ne le fit jamais à Paris comme le prétend M. du Boulay."

60. Cartulaire de Saint-Vincent, 99 et DAVID, Charles W., Robert Curthose duke of Normandy, Cambridge, 1920, p. 33. 
le clerc de sa chapelle Hoël pour remplacer Arnaud à la tête de l'évêché du Mans ${ }^{61}$. Hoël est le type même du clerc de chapelain tel que l'a défini Lucien Musset ${ }^{62}$, c'est-à-dire des homines novi " dont aucun n'est apparenté même de loin à la famille ducale " et dont " une proportion appréciable est issue de familles cléricales ". Comme Hoël, beaucoup étaient recrutés ou venaient de milieux cléricaux en faveur depuis plusieurs générations; le roi confia rapidement des sièges épiscopaux à certains de ces chapelains ou à leurs clercs, souvent " riches d'expérience administrative $^{63}$ ». Intégrant ainsi le cercle de la chapelle royale, Hoël put se familiariser avec les volontés du roi dont le choix se portait certes sur des hommes instruits et capables, mais aussi sur des hommes qui étaient d'une fidélité absolue ${ }^{64}$.

D'origine modeste, Hoël représente plus encore qu'Arnaud, un exemple de réussite et d'ascension sociale indéniable. Il est arrivé à intégrer le cercle étroit de cette " oligarchie ecclésiastique " encore en germe à son époque et qui trouvera son plein développement sous Henry ${ }^{\text {er } 65}$.

\section{L'école épiscopale du Mans à la mort de l'évêque Hoël}

Sous les épiscopats d'Arnaud et Hoël, l'école du Mans apparaît encore bien pâle; aucune trace d'élèves notoires n'émerge avant l'arrivée de Hildebert de Lavardin. Seul, Guichier, doyen du chapitre du Mans sous l'évêque Hoël est qualifié de litterarum scientia non mediocriter adornatus ${ }^{66}$. C'est à la génération suivante que cette école put donner ses fruits : le successeur de Guichier, le doyen du chapitre Geoffroi le Breton était renommé pour sa piété et son éloquence. Orderic Vital qui le connaîtra bien comme

61. ORDERIC VITAL, The Ecclesiastical..., vol. II, livre IV, p. 300. Les excuses alléguées par Samson pour refuser l'évêché du Mans qui lui aurait été proposé par Guillaume ne furent évidemment que prétextes. Samson deviendra évêque de Worcester de 1096 à 1112.

62. MusSET, Lucien, "Une voie privilégiée d'accès à l'épiscopat dans le monde anglonormand : la chapelle du duc-roi (v. 1050-v. 1150) ", L'évêque dans l'histoire de l'église, Angers, 1984, p. 51-62.

63. Ibidem, p. 55 : "Le duc-roi introduisit la même pratique dans son protectorat manceau : il installa son ancien chapelain breton Hoël comme évêque du Mans en 1080, après avoir vainement proposé ce siège à son chapelain normand Samson de Douvres, frère de l'archevêque d'York. " Cette idée germa dans ce milieu anglais, peut-être à l'imitation des usages allemands, peu avant la ruine de la monarchie anglo-saxonne.

64. Ibidem, p. 59 : nul doute que la compagnie d'Odon de Bayeux fut intéressante pour Hoël. Samson avait été le protégé d'Odon de Conteville, demi-frère du duc. Très ouvert au domaine intellectuel, Odon dirigea la formation d'un certain nombre de clercs dont il discernait le talent et notamment celle de Samson de Douvres. GALBRAITH, V. H., " Notes on the career of Samson, bishop of Worcester (1096-1112) ", English Historical review, 1967, p. 86-101.

65. M. BRETT, The English church under Henry I, Oxford, 1975, p. 110-111 : "We have a very coherent group. The men with a near stranglehold on royal patronage, the group loosely described as chaplains, gain bishoprics, the patronage of which they distribute to their relations, whom they also no doubt recommend to the king's service and favour. If they were not an aristocracy of birth, they were very near an oligarchy. "

66. Actus, p. 387. 
futur archevêque de Rouen ${ }^{67}$, l'évoque à plusieurs reprises et lui dédie des vers de sa composition ${ }^{68}$. Geoffroi le Breton fut en correspondance avec Yves de Chartres ${ }^{69}$ et le doyen de l'église de Chartres, Arnaud, le sollicita pour lui recommander son frère Jacques ${ }^{70}$. À la mort d'Hoël, il manqua d'être élu évêque du Mans et était si sûr de son succès qu'il avait préparé un somptueux banquet pour le fêter ${ }^{71}$.

Hervé, né vers 1075, manceau originaire soit du Mans soit du Maine, devint moine à l'abbaye de Bourg-Dieu ou Déols, en Berry, aux alentours de 1095, après qu'il eut accompagné peut-être son évêque Hoël lors d'un concile tenu en ce lieu. Il reçut sa première formation à l'école épiscopale du Mans lorsque précisément celle-ci est déjà sous la direction d'Hildebert ${ }^{72}$. Il laissa des études considérables sur les Saintes Écritures et la tradition patristique $^{73}$. Sa parfaite connaissance des Pères, laisserait supposer qu'il reçut un complément de formation à l'école du $\mathrm{Bec}^{74}$. Hervé de Bourg-Dieu inaugurait ainsi une nouvelle période, la plus brillante pour l'école du Mans, celle d'Hildebert de Lavardin, du chanoine Raoul du Mans, ami de Baudri de Bourgueil ${ }^{75}$, ou de Geoffroy de Gorham, né à Gorron dans le Maine, futur abbé de la prestigieuse abbaye de Saint-Albans que le précédent abbé Richard avait appelé pour prendre en charge l'école de la ville ${ }^{76}$.

Avec Hoël, toute une génération de clercs lettrés s'éteint. La même année, en 1096, Guillaume, l'ancien prieur de Saint-Calais, devenu évêque de Durham meurt le 2 janvier ; l'abbé de la Couture, Johel, le 26 juin ; l'évêque Hoël, le 29 juillet. Baudri de Bourgueil, figure marquante avec Marbode et Hildebert de Lavardin du futur « triumvirat lettré et humaniste du Val de

67. ORDERIC VITAL, The ecclesiastical..., vol. VI, livre XI, p. 172. Geoffroy le Breton était le frère de Judicaël, évêque d'Alet.

68. ORDERIC VITAL, The ecclesiastical..., vol. III, livre V, p. 94.

69. LECLERCQ, Dom Jean, Correspondance d'Yves de Chartres, Paris, 1949, Ép. 52, p. 210.

70. MERLET, René, "Lettres d'Yves de Chartres et d'autres personnages de son temps, 1087-1130", Bibliothèque de l'École des Chartes, 1855, p. 458-459.

71. ORDERIC VITAL, The ecclesiastical..., vol. V, livre X, p. 234. Au sein du chapitre qui avait toujours été divisé, Geoffroi le Breton était du " clan normand ". Ce fut l'archidiacre Hildebert de Lavardin, soutenu par le comte du Maine Hélie de La Flèche qui fut élu.

72. L'évêque Hoël choisit le vendômois Hildebert de Lavardin pour diriger son école et le nomma archidiacre. Actus, p. 398. Une lettre à l'abbé de Saint-Vincent Guillaume (Patrologie latine, t. 171, Ép. III, 21) nous apprend qu'il fut archidiacre pendant cinq ans. Par conséquent, il dut commencer à diriger l'école cathédrale aux alentours de 1091 . Lorsqu'Hoël partit pour l'Italie vers 1095, il était accompagné par son nouvel archidiacre Hildebert. MABILLON, Jean (éd.), "Venerabili Hildeberti Vita », Patrologie Latine, t. 171, col. 65-66.

73. La Patrologie latine consacre pratiquement un tome entier à ses œuvres, le tome 181 .

74. OurY, Guy-Marie, "La doctrine monastique d'Hervé de Bourg-Dieu ", La Province du Maine, 1969, p. 300-317 et 409-416.

75. Deliste, Léopold, " Notes sur les poésies de Baudri, abbé de Bourgueil ", Romania, 1872, Notice CCXLLIII.

76. KNowles, David, The Monastic order in England, Cambridge, 1949. Par la suite, Geoffroy fut l'initiateur de théâtre religieux qu'il instaura en même temps que la fête de Sainte Catherine, "Chronica monasterii S. Albani ", RILEY, H. T. (éd.), (Rolls Series 28), London, 1863, vol. IV, 73, 75. 
Loire ", ne put s'empêcher de se prêter à l'assonance des deux noms Hoël et Johel qu'il associa en leur louange, dans ses vers des Rouleaux mortuaires ${ }^{77}$.

\section{Le rôle politique des évêques Arnaud et Hoël}

\section{Guillaume le Conquérant et le comté du Maine}

L'évêché du Mans, surtout en 1065, est un évêché hautement stratégique. Disposer de l'évêché était indispensable pour qui voulait tenir le comté du Maine. Dans ce contexte, Arnaud et Hoël eurent un rôle déterminant à jouer. À la veille de leur épiscopat, ils ont déjà consacré une grande partie de leur vie à leur formation intellectuelle qui fait d'eux des clercs lettrés, mais le choix de Guillaume, en ces circonstances, fut essentiellement politique ${ }^{78}$.

À la mort de l'évêque angevin Vulgrin en 1065, le duc de Normandie Guillaume, maître de la cité du Mans depuis $1063^{79}$ a les mains libres pour y nommer un évêque de son choix, d'autant qu'à partir de 1060, après la mort du comte Geoffroy Martel, le comté d'Anjou allait être affaibli avec les comtes Geoffroy le Barbu et Foulque le Réchin (1060-1109). Sous les épiscopats d'Arnaud et Hoël, c'est-à-dire dans la seconde moitié du XI ${ }^{\mathrm{e}}$ siè-

77. Patrologie latine, t. 166, col. 1083, et BourgueIL, Baudri de, Baldricus Burgulianus Baudri de Bourgueil Carmina, t. I, Tilliette, Jean-Yves (éd.), Paris, 1998, n 18 : In rotulo Cenomannensi : Singultus duplices rotularis pagina profert :/Primum nanque Iohel, denique flevit Hoel./Abbas alter erat, alter fuit ordine presul./Hi Cenomannis sol scilicet extiterant. "Ce rouleau de parchemin émet un double sanglot : il pleure Joël d'abord et ensuite Hoël. L'un appartenait à l'ordre abbatial, l'autre à l'ordre épiscopal : ils étaient le soleil des Manceaux..."

78. Les études récentes d'Olivier Guillot, de Bruno Lemesle ou de Jean-Hervé Foulon nous dispensent ici d'analyser le rôle spécifiquement religieux d'Arnaud ou Hoël qui en tant qu'évêques avaient des pouvoirs d'ordre, de magistère et de juridiction et une relation fondamentale à l'Église : GuILLOT, Olivier, Le Comte d'Anjou et son entourage au X⿸厃 siècle, Paris, 1972; LEMESLE, Bruno, Les Évêques du Mans..., op. cit., et La Société aristocratique dans le Haut-Maine (XI -XIt siècles) Rennes, PUR, 1999; FoULON, Jean-Hervé, La réforme de l'Église..., op. cit.

79. Le jeune comte du Maine Herbert II, sur les conseils de sa mère Berthe de Blois, veuve du comte du Maine Hugues IV décédé en 1051, s'était reconnu vassal du duc Guillaume tandis que sa sœur Marguerite se fiançait au jeune fils aîné de Guillaume, Robert Courteheuse. LATOUCHE, Robert, Histoire du comté du Maine, Paris, 1910, p. 33. «On convint que si Herbert décédait sans enfants le comté du Maine passerait au duc de Normandie. " Lorsque le jeune comte Herbert II meurt sans enfants le 9 mars 1062, il apparaissait comme légitime que le duc de Normandie puisse récupérer l'héritage manceau. Mais les barons manceaux choisirent à la place Gautier III de Vexin, époux de Biote, fille de l'ancien comte du Maine Herbert Éveille-Chien, ce qui obligea le duc, en 1063, à conquérir le comté par la force. Guillaume prit cependant toujours soin de reconnaître la suzeraineté angevine. Le jeune Robert Courteheuse, comte du Maine en titre, et sa fiancée Marguerite du Maine prêtèrent donc hommage en sa présence à Alençon au nouveau comte d'Anjou Geoffroy le Barbu, puis vingt ans plus tard, en 1081, au comte Foulque le Rechin. En échange, le comte d'Anjou reconnut les droits directs de Robert Courteheuse sur le comté du Maine. ORDERIC VITAL, The ecclesiastical..., vol. II, livre IV, p. 311. 
cle, les sept évêques normands de la province de Rouen appartiennent tous, soit directement au lignage ducal, soit à un lignage aristocratique ${ }^{80}$. Ce n'est évidemment le cas ni pour Arnaud, ni pour Hoël. Mais, pour Le Mans, il importe surtout au duc de pouvoir compter sur des hommes dévoués; or l'absence de toute attache lignagère de la part de nos évêques, en cette contrée fraîchement conquise, peu sûre et durement convoitée, constituait plutôt une assurance de fidélité. Arnaud et Hoël, tous deux sans appui parental connu, ont grandi dans le milieu de l'Église auquel ils doivent tout : le chapitre au sein duquel ils se sont formés, le pape lui-même Alexandre II qui a toléré et accepté qu'Arnaud, ce fils de prêtre, devienne évêque. Mais ils sont aussi redevables au duc-roi Guillaume qui leur a accordé sa confiance et a permis à Hoël de devenir clerc de sa chapelle.

Pourtant ces fidélités personnelles, même sûres, sont insuffisantes. Elles doivent s'accompagner d'autres soutiens dont le duc Guillaume doit connaître les appartenances car il sait que les hommes de son temps quels qu'ils soient, appartiennent à une terre. Arnaud est originaire de l'Avranchin; Hoël, quant à lui, sans qu'on connaisse sa région d'origine, porte un nom breton, ce qui déjà est une indication. Les études récentes de Mathieu Arnoux, Hubert Guillotel, Katharine S. B. Keats-Rohan, Cassandra Potts, Eleanor Searle ${ }^{81}$ ont montré le rôle déterminant et l'histoire complexe de l'Avranchin partagée entre influences bretonnes, normandes et vikings depuis le $\mathrm{IX}^{\mathrm{e}}$ siècle.

Avec Guillaume le Bâtard, la question de cette frontière ouest-sud-ouest entre la Normandie et la Bretagne devient un enjeu essentiel ${ }^{82}$ et tenir le Maine est fondamental du fait de sa position intermédiaire entre la Normandie et son adversaire le plus résolu, l'Anjou. La conquête de la " frontière " ouest normande avait activement commencé depuis pratiquement le début du XI ${ }^{\mathrm{e}}$ siècle et le duc Robert le Magnifique, père de Guillaume, avait sans aucun doute marqué un avantage, en faisant avancer les limites de son duché depuis la Sélune jusqu'au Couesnon et en obli-

80. Jean d'Ivry (1060-1067) pour Avranches, Odon de Conteville (1049-1097) pour Bayeux, Hugues d'Eu (1049-1077) pour Lisieux, Jean d'Ivry encore pour Rouen (1067-1079) sont de lignage ducal; Geoffroy de Montbray (1049-1093) pour Coutances, Gilbert fitz Osbern ou de Breteuil (1071-1112) pour Evreux, Robert de Ryes (vers 1070-vers 1081) pour Sées et Guillaume Bonne-Ame (1079-1110) pour Rouen sont de lignage aristocratique.

81. Entre autres travaux, ARnOux, Mathieu, " Before the Gesta Normannorum and beyond Dudo. Some evidence on the first Norman historiography ", Anglo-Norman Studies, 1999; Guillotel, Hubert, La Bretagne des saints et des rois, $v^{e}-X^{e}$ siècle, Rennes, Ouest-France, 1984 ; KeAts-Rohan, Katharine S. B., "Une charte de l'abbé Mayeul... ", art. cit.; idem, "Bibliothèque municipale d'Avranches... ", op. cit.; POTTS, Cassandra, " Normandy or Brittany? A conflict of interest at Mont Saint-Michel (966-1035) ", Anglo-Norman Studies, 1989, p. 135-156; SEARLE, Eleanor, "Predatory Kinship and the creation of Norman power, 840-1066 ", Berkeley/Los Angeles/London, 1988.

82. BATES, David, Normandy before 1066, London/New-York, 1982, p. 57 : "With William II, this dispersal of effort ceased. His wars were consistently aimed to defend or expand the Norman frontiers " et p. 75-83: "The stabilisation of the Norman frontier was the work of William II... but it is also clear that Normandy's history entered a new phase in William's time. " 
geant le comte de Bretagne Alain III à se placer dans sa vassalité ${ }^{83}$. Il revenait au jeune duc Guillaume de consolider cette avancée ce qu'il fit en conquérant le Maine dès 1063. Cependant la mainmise sur ce comté sera toujours mal assurée. Le duc devra compter avec l'opposition naturelle et permanente de la maison d'Anjou mais aussi avec l'opposition interne des nombreux barons manceaux toujours à la recherche d'une lignée comtale héréditaire " légitime " et les sentiments plutôt pro-angevins de la population $^{84}$. Ce danger est d'autant plus grand qu'il touche le cour même de l'Église du Mans. Le chapitre cathédral lui-même est partagé entre les partisans des Angevins et ceux des Normands. C'est dire l'importance du choix des hommes, de ceux que le prince devait placer aux postes clefs de la hiérarchie ecclésiastique mancelle, de l'évêque bien sûr, mais aussi du doyen du chapitre, de chacun des chanoines, des abbés des principales abbayes de la cité. La connaissance des réseaux, des groupes de parenté, amis, hommes, épouses et alliés ainsi que celle des terres qui sont entre leurs mains jouent un rôle essentiel et d'autant plus complexe que ces lignages ne respectent pas les "frontières " car leur patrimoine et leurs terres les outrepassent ou les chevauchent. Avec le jeu des mariages, des remariages, des inféodations, sous-inféodations, et des héritages, on aboutit à des résultats extrêmement subtils comme nous le montrent toutes les études prosopographiques. Dans le cas de l'Avranchin, la situation se complique du fait de l'imbrication ancienne des Bretons de l'est avec les Normands de l'ouest et ce depuis le IX ${ }^{\mathrm{e}}$ siècle. Des Bretons ont pu s'installer dans l'Avranchin depuis $867^{85}$ et jusqu'en 1014 au moins, cette région est le théâtre d'une lutte continue entre groupes Vikings, Bretons et Normands qui cherchaient à s'y établir ${ }^{86}$. L'installation de ces Bretons en ces régions de confins a laissé des traces dont les noms témoignent encore en plein $\mathrm{XI}^{\mathrm{e}}$ siècle ${ }^{87}$.

83. The gesta Normannorum Ducum of William of Jumièges, Orderic Vitalis, and Robert of Torigni, VAN HouTs, Elisabeth M. C (éd.), Oxford, 1995, Book VI, 56-59-78-79.

84. LEMESLEN, Bruno, « Le discours... ", art. cit., p. 17-32.

85. GuILLOTEL, Hubert, op. cit., p. 317-318 : Après la mort de Robert le Fort à Brissarthe en 866 , Charles le Chauve dut, en 867 , concéder à Salomon de Bretagne " le comté de Cotentin avec tous ses fiscs, domaines royaux et abbayes... à l'exception de l'évêché " (Annales de Saint-Bertin, Grat, Félix, Vielliard, Jeanne et Clemencet, Suzanne [éd.], Paris 1964, p. 136-137). "Cette cession du Cotentin impliquait l'abandon préalable de l'Avranchin..."

86. GuLLOTEL, Hubert, op. cit., p. 402 : « En 1014, la ville de Dol sera incendiée à la suite de la venue d'une flotte scandinave sur les côtes nord de la Bretagne. "

87. Musset, Lucien et CHANTEuX, Henri, «Essai sur les invasions bretonnes et normandes dans le Maine aux $\mathrm{IX}^{\mathrm{e}}$ et $\mathrm{x}^{\mathrm{e}}$ siècles ", Bulletin de la Commission historique et archéologique de la Mayenne, 1972, p. 53 et GullLotel, Hubert, op. cit., p. 327. C'est le cas de notre évêque Hoël, mais aussi de l'abbé Hoël de Saint-Vincent, du doyen de la cathédrale du Mans, Geoffroy le Breton, de l'abbé Johel de la Couture. De plus, beaucoup de seigneurs bretons de cette région frontière tenaient à marquer leur différence en ajoutant à leur nom un surnom soulignant leur origine bretonne comme Britannicus gente, Brito..., Keats-Rohan, Katharine S. B., " The Bretons and Normans in England 1066-1154 : the family, the fief and the feudal monarchy ", Nottingham Medieval Studies, t. XXXVI, 1992, p. 54 : "The Bretons are unusual among the mediaeval peoples for having a highly developed awareness of their national and cultural distincness. " 
Dans la période qui précède immédiatement l'épiscopat d'Arnaud, en prévision peut-être de son expédition anglaise, le duc Guillaume fut alors particulièrement attentif à la situation de cette frontière occidentale. Il voulait contrôler ces Normands du Cotentin et de l'Avranchin, restés longtemps indépendants de l'autorité des comtes de Rouen et mêlés à une population bretonne installée depuis longtemps sur place. À cette fin, le duc procéda à un remaniement général et à une réorganisation administrative et militaire de la région. Il confie vers 1055/1056 la défense de cette région-frontière à l'homme qu'il estime le plus apte à protéger ses intérêts dans l'Ouest, son demi-frère Robert de Conteville, devenu comte de Mortain ${ }^{88}$. À la même époque, vers 1054, Richard Goz, autrefois familier du fidèle Néel de Saint-Sauveur apparaît dans les actes du duc comme vicomte d'Avranches ${ }^{89}$. En outre, Guillaume devait s'assurer les fidélités non seulement de ses propres Normands, mais aussi des Bretons dont il exigea qu'ils reconnaissent sa suzeraineté ${ }^{90}$. De cette façon, le duc Guillaume pouvait tenir une région grâce à des alliés fidèles issus des familles seigneuriales du comté. Arnaud appartenait précisément à cette région-frontière et nous pouvons supposer qu'Hoël était un de ces alliés bretons si sûrs pour le duc.

\section{Arnaud, agent de Guillaume le Conquérant : la mise en place de l'abbé Johel de la Couture}

\section{La famille normande de Johel}

Élu évêque, Arnaud va s'attacher à remplir son rôle et en plusieurs occasions montrer son zéle. Bruno Lemesle note justement qu'Arnaud de « créature du duc de Normandie qu'il était... se montra de surcroît une bonne courroie de transmission pour son maître laïque dans le comté ${ }^{11}$ ». Sa position hostile à l'égard de Marmoutier dès 1068, son rôle ambigu lors de la "Commune " de 1070, son intervention dans la querelle de Saint-Malo de

88. Robert de Conteville ou de Mortain est le fils d'Herluin de Conteville et d'Herlève ou Arlette, elle-même mère du duc Guillaume mais que le duc Robert le Magnifique avait mariée vers 1030 à Herluin de Conteville.

89. FAuroux, Marie, Recueil des actes des ducs de Normandie (1066-1166), Caen, 1961, Actes 159-199. En épousant la sœur de Robert de Mortain, Emma, Richard se rattachera à la famille du duc lui-même.

90. Dès 1951, MusSET, Lucien : «Aux origines de la féodalité normande : l'installation par les ducs de leurs vassaux normands et bretons dans le comté d'Avranches ", Revue Historique de Droit français et étranger, 1951, p. 150, attirait l'attention sur l'importance et le rôle de ces vassaux dans la stratégie du duc. Main de Fougères qui avait reconnu la suzeraineté du comte de Bretagne, Conan, reconnaît dès 1056, celle du duc Guillaume. FAURoux, Marie, Recueil des actes..., op. cit., Actes 160, 161, 162. C'est également le cas pour Rivallon de Dol (un des nombreux frères du puissant Junguené, archevêque de Dol [vers 1008-1035]) qui dut prêter hommage à Guillaume pour sa terre de Céaux, située entre la Sélune et le Couesnon, c'est-à-dire dans cet espace nouvellement acquis pour la Normandie.

91. LEMESLE, Bruno, La société aristocratique..., op. cit., p. 72. 
Sablé à partir de 1076, montrent qu'il fut, pour le roi Guillaume, un véritable agent politique efficace et opiniâtre ${ }^{92}$.

Symptomatique est le rôle déterminant que va jouer Arnaud dans la mise en place d'un homme du roi à la tête de l'abbaye mancelle de la Couture. En 1073-1074, Arnaud dépose l'abbé de la Couture Renaud et le remplace par un homme du roi d'Angleterre du nom de Johel ${ }^{93}$. Cette déposition et la désignation autoritaire d'un abbé par un puissant laïc ouvrent une crise politique et religieuse qui se poursuivra jusqu'en 1080. Sur le plan politique, cette crise est exemplaire de la manière du roi Guillaume, qui, lorsqu'il veut choisir un homme sûr, va le chercher au sein d'un lignage fidèle dont l'assise territoriale est contrôlée. Sur le plan religieux, cette crise se déroule entre 1074 et 1080, c'est-à-dire lors d'une des périodes les plus difficiles du pontificat de Grégoire VII, à un moment où désormais, même le roi d'Angleterre doit composer avec les autorités de l'Église Romaine de plus en plus présentes et agissantes dans la région. Braver les plus hautes autorités de l'Église nécessitait pour le roi d'avoir sur place un homme sûr : ce sera l'évêque Arnaud qui jouera à la fois de son autorité religieuse mais aussi du poids politique que l'appui du roi Guillaume le Conquérant lui assure.

La déposition de l'abbé Renaud se situe après le printemps $1073^{94}$ au moment où le roi reprend en mains le comté, déstabilisé depuis 1069, par une nouvelle révolte des barons manceaux ${ }^{95}$. Nous connaissons l'homme de Guillaume, Johel, grâce à une donation que font, en 1082, à l'abbaye de la Couture et sur sa demande, ses frères Gautier et Raoul Dastin ${ }^{96}$. Ce don comprend l'église de Vezins (diocèse d'Avranches) avec ses appartenances, ainsi que six acres de terres. Les deux frères donnent également la dîme de ce qu'ils possédaient en moutons, vaches, chevaux, aussi bien à Vezins que dans toute la Normandie et ailleurs. Le troisième jour, en la chapelle de son château ${ }^{97}$, Guillaume des Biards, localité voisine de Vezins, ajoute à ces dons une terre proche d'un verger pour y planter une vigne ${ }^{98}$.

92. Ibidem, p. 103.

93. La date du début de cette crise nous est fournie par une lettre, datée de 1079, de l'archevêque Gebuin de Lyon à l'archevêque Raoul de Tours et à ses suffragants où il est fait allusion " aux tourments " que le roi d'Angleterre fait subir à l'abbé Renaud depuis cinq ans, Recueil des Historiens des Gaules ou de la France, Paris, 1877, [en abrégé RHF], t. XIV, p. 668-669.

94. Le 30 mars 1073, à la demande de Renaud, encore abbé de la Couture, et en présence de l'évêque Arnaud, Guillaume, alors à Bonneville sur Touques, confirme à l'abbaye la fondation de Solesmes faite en 1010 (Cartulaire de la Couture, IX). Dans le cartulaire de Saint-Vincent, Acte 175, on peut lire : "Acta autem fuit... eo videlicet anno quo Robertus... comitatum Cenomannensem recuperavit. "Bien que vaguement datée par les éditeurs de 1067-1074, on peut supposer qu'elle date du printemps 1073, moment où l'autorité normande est rétablie.

95. LEMESLE, Bruno, La société aristocratique..., op. cit., p. 72. Des liens ont pu exister entre Renaud, la Couture et les chefs de la révolte.

96. Gallia Christiana, t. XI, Instrumenta, IV, col. 107.

97. Ibidem.

98. Ibid. 
L'acte révèle l'existence de trois frères de la famille Dastin dont les biens semblent considérables (terres, animaux d'élevage) et répartis sur toute la Normandie. Raoul, Gautier et Johel sont en réalité les membres d'une famille seigneuriale majeure du comté de Mortain, responsable de sa défense sur sa frontière sud et vassale de celle des Biards ${ }^{99}$. Guillaume des Biards est le fils d'Avenel des Biards à qui Robert de Mortain inféoda toute une partie des terres situées au nord de la Sélune. Le fief des Biards surveillait la rivière de Sélune qui, jusqu'à Robert le Magnifique, avait servi de frontière avec la Bretagne ${ }^{100}$. Le seigneur des Biards est détenteur d'une forteresse dont l'existence est attestée ici (in capella castri), mais dont la construction dut être antérieure et dater du temps d'Avenel ${ }^{101}$. À côté de l'aîné Guillaume des Biards, détenteur du château, son frère Renouf (Ragnulf) semble être un fidèle de Robert de Mortain dans l'entourage duquel il apparaît nettement en $1082^{102}$. Les Dastin comme les Biards sont bien des fidèles de la famille de Guillaume ${ }^{103}$.

Cette donation à la Couture révèle tout un réseau familial et seigneurial. Les donateurs sont tous des Normands. Le prénom breton Johel donné au benjamin de la famille, destiné à être moine, ne manque cependant pas d'intriguer, car on sait que, dans les familles aristocratiques, les prénoms étaient rarement donnés au hasard ${ }^{104}$. Le roi sait compter sur ce lignage avranchin, dont la fidélité est éprouvée et à qui on a confié la défense d'un

99. PouesSEL, Jean, "Les structures militaires du comté de Mortain ( $\mathrm{XI}^{\mathrm{e}}$ et XII ${ }^{\mathrm{e}}$ siècles) ", Revue de l'Avranchin et du pays de Granville, 1981, p. 55. Des traces de la motte des seigneurs Dastin existent encore dans la commune de Vezins.

100. Avenel (Avenal) des Biards aurait participé à la conquête de l'Angleterre. Wace le cite en ces termes : "D'Avrancin i fut Richars/Ensemble od li cil des Biars.../Des Biards $i$ fiers Avenals " (WACE, Roman de Rou, Rouen, Pluquet, t 2, 1827, p. 242-247). Il est placé à côté du vicomte d'Avranches.

101. Le château des Biards dominait la Sélune, au sommet d'un coteau escarpé et était pratiquement inaccessible par le Sud.

102. KeATs-RoHAn, Katharine S. B. " The Bretons and Normans... ", art. cit., p. 50 note 31. Le 24 juin 1082, Renouf des Biards témoigne, dans une donation pour Marmoutier, aux côtés du roi Guillaume, de ses fils, ainsi que de Robert de Mortain, de son fils et de la comtesse Mathilde. (Regesta Regum Anglo-Normannorum 1066-1154, DAVIS, H. W. [éd.], Oxford, 1913, n 146 et Regesta Anglo-Normannorum The Acta of William I [1066-1087], BATES, David [éd.], Oxford, 1998, Acte 204.) Il participe également entre le 24 juin et l'automne 1082, à la fondation de la collégiale de Mortain fondée par Robert et sa femme Mathilde (Regesta..., op. cit., Acte 215.) Ajoutons que vers 1062-1067, Raoul Dastin est témoin d'une donation faite par un certain Roger de l'église de La Bazoge (Manche, arrondissement d'Avranches) à l'abbaye bretonne de Saint-Sauveur de Redon. Cette donation est approuvée par le comte Robert de Mortain et par l'évêque d'Avranches, Cartulaire de l'abbaye de Redon, Courson, Aurélien de (éd.), Paris, 1863, acte CCCXXVI, p. 277-278. Cet acte mériterait une étude approfondie.

103. Cette famille Dastin était originaire de Haute-Normandie et dut émigrer vers la Basse Normandie et la région de Mortain. BouvRIS, Jean-Michel, " Pour une étude prosopognaphique des familles nobles d'importance moyenne en Normandie au XI ${ }^{\mathrm{e}}$ siècle : l'exemple du lignage des Dastin ", Annales de Normandie, 4, 1984, 435-437. L'auteur situe la première implantation des Dastin sur la basse Dives.

104. Johel devient prieur de la Couture en 1073. Doit-il ce prénom à son ascendance maternelle? 
château. Ces familles s'enracinent par alliances et mariages et édifient tout un réseau d'hommes aux intérêts semblables en établissant certains des leurs à des postes importants, religieux ou militaires.

\section{L'évêque Arnaud et l'Église}

Comme souvent $\mathrm{au} \mathrm{XI}^{\mathrm{e}}$ siècle, cette crise politique devient religieuse car elle touche à la nomination d'un abbé et s'ouvre au moment où entrent en scène les principaux protagonistes d'une Église au plus fort de son action réformatrice en France.

Grégoire VII, pape depuis le 22 avril 1073, accélère le mouvement de la Réforme de l'Église et le 16 mars 1074 nomme Hugues de Die légat du SaintSiège en France et en Bourgogne. Dès lors, Hugues de Die est vraiment à la tête de l'Église de France et va développer une activité considérable, spécialement dirigée contre les évêques simoniaques. Sur place, Raoul I de Langeais, l'archevêque de Tours dont dépend l'évêque du Mans Arnaud est, dès 1074, menacé de suspension pour simonie, car nommé par le roi de France. Mais l'archevêque a aussi la chance d'être ménagé par le pape qui s'en sert comme d'“ un relais efficace à l'autorité du Saint-Siège Apostolique » dans l'Ouest ${ }^{105}$. Pour le roi Guillaume le remplacement de l'abbé de la Couture était essentiel mais l'évêque Arnaud, chargé de l'affaire dès 1073-1074, est déjà englué dans un difficile conflit entre Marmoutier et la Couture précisément ${ }^{106}$.

En 1078, quatre ans après, la crise perdure : l'abbé Renaud, protestant d'avoir été chassé injustement et arguant du caractère simoniaque évident de l'élection du nouvel abbé Johel, menace de porter sa cause à Rome ${ }^{107}$. De son côté, l'archevêque Raoul, suspendu pour simonie au concile de Poitiers du 15 janvier 1078 et bien que réhabilité le 9 mars par Grégoire VII, préfère se montrer prudent ${ }^{108}$. Dans une lettre à Arnaud, l'archevêque s'inquiète et lui conseille de rendre justice à Renaud en abandonnant cette cause indéfendable ${ }^{109}$.

Mais l'affaire rebondit car Renaud va trouver un soutien de poids en la personne de l'archevêque de Lyon, Gebuin qui reçoit du pape, le 19 avril 1079, la primatie sur les provinces de Rouen, Sens et Tours, ce qui lui per-

\footnotetext{
105. Foulon, Jean-Hervé, La Réforme de l'Église..., op. cit., p. 102.

106. LEMESLE, Bruno, La Société aristocratique..., op. cit., p. 102-103. C'est justement lors d'une tentative de conciliation entre les deux parties, en 1076, qu'on constate l'absence de l'abbé Renaud, sans doute emprisonné par Arnaud qui, sur le moment, prétend même faire office d'abbé à sa place. Voir LaURAIN, Ernest, Cartulaire manceau de Marmoutier, Laval, 1911 et 1945, t. 2, 5, p. 69-70.

107. RHF, t. XIV, p. 667.

108. PonTAL, Odette, Les conciles de la France capétienne jusqu'en 1215, RHT, CNRS, Paris, 1995, p. 182. Au concile de Poitiers, Hugues de Die suspendit et sanctionna près d'une dizaine de prélats! Grégoire VII, effrayé par le nombre de sanctions qui risquait de lui aliéner l'épiscopat et le roi de France, au moment de la lutte du Sacerdoce et de l'Empire, les annula le 9 mars 1078.
}

109. $R H F$, t. XIV, p. 667. 
met d'intervenir directement dans les affaires du diocèse du Mans. Gebuin prend vigoureusement la défense de Renaud qu'il accompagne à Rome à cet effet. Dans une lettre adressée à l'archevêque Raoul et à ses évêques, Gebuin leur ordonne de réhabiliter et de rétablir Renaud dans ses fonctions; il jette l'anathème sur Johel qu'il accuse des pires turpitudes et suspend Arnaud qui a consacré cet abbé simoniaque ${ }^{110}$. Pourtant, le 24 avril 1080, c'est un retournement complet de situation : Grégoire VII non seulement installe Johel abbé de la Couture mais dépose aussi Renaud qu'il accuse de mensonge et d'ambition en lui interdisant d'exercer aucune responsabilité dans aucun monastère ${ }^{111}$ ! Pourquoi une telle décision qui fait de ce pauvre Renaud la victime de ce jeu de dupes? Entre 1076 et 1080, les relations entre le pape et le roi Guillaume sont tendues. Le pape compte réaliser pleinement sa politique de réforme alors que le roi traverse ses plus sévères revers ${ }^{112}$. Lorsque l'archevêque de Rouen Jean d'Ivry meurt le 9 septembre 1079, Grégoire VII hésite à reconnaître Guillaume Bonne-Ame que le roi avait nommé à ce siège. De son côté, le roi Guillaume ne pouvait admettre qu'un simple archevêque comme Gebuin, avec ou sans le consentement du pape, dépose, sans son accord, un prélat qui relève de sa souveraineté. Au début de 1080, Guillaume envoie à Rome une mission de conciliation auprès du pape qui ne peut réellement rompre avec ce roi réformateur que dans le fond il estime ${ }^{113}$. Le pape cède donc : l'évêque Arnaud et l'abbé Johel sont réinstallés sur son ordre et Guillaume Bonne-Ame reconnu archevêque de Rouen. Arnaud est parvenu à ses fins. Il était temps : l'évêque allait avoir 70 ans.

\section{L'évêque Hoël et Robert Courteheuse}

En nommant Hoël évêque du Mans après la mort d'Arnaud en 1081, Guillaume le Conquérant escomptait bien la même fidélité et le même dévouement de la part d'un homme formé au sein de sa chapelle, parmi ses serviteurs les plus dévoués. Mais du fait de l'opposition farouche du comte d'Anjou Foulque le Rechin, Hoël ne put être consacré normalement par l'archevêque de Tours et dut attendre le 21 avril 1085 pour l'être par l'archevêque de Rouen, Guillaume Bonne-Ame, au cœur même du duché normand ${ }^{114}$. De ce fait, l'évêque ne put servir le roi que peu de temps.

En 1087, à la mort de Guillaume le Conquérant, Robert Courteheuse devenait effectivement comte du Maine ${ }^{115}$. Il lui revenait désormais de venir

110. $R H F$, t. XIV, p. 668-669.

111. $R H F$, t. XIV, p. 648.

112. En 1076, le roi est mis en échec au siège de Dol mais on pense surtout à la rébellion de son fils aîné, Robert Courteheuse qui dut éclater à la fin de 1077-1078. Une réconciliation du père et du fils dut se faire au début de 1080, car une lettre du 8 mai 1080 de Grégoire VII à Robert se réjouit de cette bonne nouvelle. Le même jour, le pape écrivit aussi des lettres de courtoisie à Guillaume et à Mathilde. (David,Charles W., Robert Curthose..., op. cit., p. 30, note 55).

113. Douglas, David C., William the conqueror, Londres, 1964, p. 338-341: " And even in 1080 at the height of their disagreement he could refer to the Conqueror as a jewel among princes. " 114. Actus, p. 383 et Gallia Christiana, t. XI, col 39.

115. DAVID, Charles W., Robert Curthose..., op. cit., p. 11, note 79. 
s'imposer au Mans où l'attend la garnison placée par son père, et le fidèle et loyal évêque Hoël ${ }^{116}$. En août 1088, Robert Courteheuse, après une sévère campagne à travers le Maine, reçoit apparemment sans difficultés l'hommage des principaux barons manceaux, Geoffroy de Mayenne, Robert le Bourguignon, Hélie de La Flèche ${ }^{117}$. Pourtant dès 1089, une nouvelle révolte des barons se préparait.

L'absence quasi totale d'une réelle autorité normande sur le comté rendit, en réalité, la tâche d'Hoël très difficile, voire impossible. L'historiographie traditionnelle est sévère pour Robert Courteheuse; si l'on s'en tient aux seuls actes de la pratique, il est certain que Robert n'agit comme comte du Maine que de façon très fugitive. Du vivant de son père, il témoigne ici et là, en tant que comte ${ }^{118}$. Entre 1087 et son départ pour la croisade en 1096, il semble délaisser peu à peu ses pouvoirs et même si, entre 1087 et 1091, il est encore légitimement reconnu comme ayant des droits sur le comté ${ }^{119}$, dés la fin de 1089, son autorité n'y était déjà plus manifeste et luimême semble ne plus apparaître dans le Maine ${ }^{120}$.

\section{L'évêque Hoël et les barons manceaux, 1085-1091}

Il conviendrait de rééxaminer les responsabilités de Robert Courteheuse vis-à-vis d'un comté dont le contexte politique avait changé et que déjà, du temps du Conquérant, il était difficile de tenir. Il reste que l'évêque normand Hoël s'est trouvé totalement isolé et sans aucun appui, face à l'aristocratie mancelle en rébellion constante, face à son propre chapitre et même face à l'inaction du roi Guillaume le Roux. Dans ce contexte difficile, l'évêque gardera toujours une absolue loyauté à la dynastie normande. Le jeune et ambitieux Hélie de La Flèche ${ }^{121}$ ne s'y trompa pas lorsqu'il crut habile de faire prisonnier ce tenant farouche de la cause normande ${ }^{122}$.

116. ORDERIC VITAL, The ecclesiastical..., op. cit., vol. IV, livre VIII, p. 150-151.

117. Cartulaire de Saint-Vincent, 532 : Robert signe en tant que "Normannie princeps et Cenomannorum comes".

118. DAVID, Charles W., Robert Curthose ..., p. 10, note 34. Avant 1066, en 1068, 1074. Après 1081, Robert disparaît et fin 1083, s'exile à nouveau pour ne réapparaître qu'à la mort de son père. 119. Regesta Regum..., op. cit., DAVIS, H. W. C. (éd.), Actes 308 (24 avril 1089), 310 (1089 Eu), 324 (1087-1091).

120. Robert eut-il des problèmes de santé? Par deux fois, le comte Foulque le Rechin en 1089 puis Hoël allèrent en Normandie pour le rencontrer et le trouvèrent malade. Le jugement de C. W. David est rude : "Through weakness and inertia he had allowed a splendid territory, which the Conqueror had been at much pains to win, to slip from his hands without striking blow. " Judith A. Green s'insurge contre cette vision négative du règne de Robert qui repose beaucoup sur l'étude pionnière, mais très institutionnelle de Charles H. HASKINS, Norman Institutions, Cambridge, 1918. Voir : GREEN, Judith A., "Robert Curthose reassessed ", Anglo-Norman studies, 1999. Le projet (en cours) d'une édition des actes de Robert Courteheuse aiderait à une plus juste réévaluation de son gouvernement.

121. Hélie de La Flèche est héritier légitime du comté car petit-fils du comte Herbert Éveille-Chien par sa mère Paule, Actus, p. 385.

122. Lemesle, Bruno, La société aristocratique..., op. cit., p. 37 : «Un authentique mouvement de paix " se déclencha pour la délivrance de l'évêque. 
L'investiture d'un autre " légitime " comte du Maine, Hugues d'Este, ou Hugues $\mathrm{V}^{123}$, représentait toutefois un réel danger et Hoël crut de son devoir d'en avertir le duc Robert, alors en Normandie. "Plongé dans la paresse et adonné à la poursuite de ses plaisirs ", selon Orderic Vital, il eut tout de même la lucidité politique de recommander à l'évêque de préserver son droit de patronage sur l'évêché ${ }^{124}$. De fait, fidélité, calcul politique ou intérêt bien compris, lorsque Hugues V lui demanda d'accepter son investiture, Hoël refusa ${ }^{125}$. Forcé de quitter la ville, l'évêque, qui devait en outre affronter une rébellion des clercs de son chapitre ${ }^{126}$, finit par trouver protection auprès de Robert le Bourguigon, à Sablé, où il fit prudemment transporter le trésor de sa cathédrale ${ }^{127}$. Essayant vainement de trouver du secours auprès de Guillaume le Roux, en Angleterre où il séjourna quatre mois ${ }^{128}$, l'évêque revint près de Sablé, au prieuré de Solesmes qui était à l'abbaye de la Couture et dont Johel était l'abbé. Mais ces appuis dataient du temps où l'implantation normande était bien établie et n'avaient plus guère de portée. La vente du comté du Maine par Hugues V à Hélie de la Flèche rendait les droits de Robert sur le comté définitivement caducs et la dégradation générale de la situation vidait le rôle politique de l'évêque de son objet. Hoël, retourné à sa mission religieuse, mourait le 29 juillet 1096, avant que le roi Guillaume le Roux, chargé de la Normandie depuis le départ de son frère Robert Courteheuse en croisade ${ }^{129}$, ne décide d'intervenir à nouveau dans le comté du Maine.

L'absence de toute volonté politique ne permit jamais à Hoël de pallier la perte d'influence de l'autorité normande sur le comté. Son remplacement par l'évêque Hildebert de Lavardin marque la fin la prépondérance nor-

123. ORDERIC VITAL, The ecclesiastical..., op. cit., vol. IV, livre VIII, p. 192. Il est aussi petitfils du comte Herbert Éveille-Chien par sa mère Gersent. Son père était Azzon, marquis d'Este, cf. infra, note 144 .

124. La faiblesse de Robert Courteheuse souvent dénoncée par Ordéric Vital est aussi indiquée par les Actus, p. 386 : "Ipse autem Rotbertus ultra modum inertie et voluiptati deditus."

125. Actus, p. 386- 387.

126. Actus, p. 387-389. Il s'agit de la rébellion menée par le chanoine Hilgot.

127. Foulon, Jean-Hervé, La Réforme de l'Église..., op. cit., p. 114-122. Il faut remarquer l'importance et l'ampleur de la politique lignagère d'un grand baron comme Robert le Bourguignon apparenté ou lié aux grandes familles de France, Bourgogne, Aquitaine Anjou et Bretagne. LEMESLE, Bruno, La société aristocratique..., op. cit., p. 42-43. En protégeant le normand Hoël, ce puissant baron, notoirement proche de la maison d'Anjou à qui il devait la seigneurie de Sablé, pouvait se permettre une telle largeur de vue et choisir librement ses alliances à la différence d'un Hélie de La Flèche, héritier éloigné d'un simple comté, au rayonnement politique nécessairement plus étroit.

128. Le 27 janvier 1091, Hoël est à Douvres pour témoigner dans un acte de Jean, évêque de Bath et toujours en 1091, à Hastings, auprès du roi Guillaume le Roux, dans la confirmation des biens de l'église de Salisbury. Il dut rentrer vers le printemps, en avril-mai 1091. DAVIS, H. W. C., Regesta Regum anglo-normannorum, n $^{\circ} 315$ et 319.

129. L'abbé Jarenton de Saint-Bénigne de Dijon arrangea l'accord entre les deux frères avant Pâques 1096. Cet accord fut confirmé à Bayeux par Robert le 24 mai. DAvis, H. W. C., Regesta Regum..., op. cit., n ${ }^{\circ} 376$. 
mande " première manière " et prépare aux renversements d'alliances du règne d'Henry I ${ }^{\text {er } 130}$.

\section{Arnaud et Hoël, bilan de deux itinéraires}

\section{Arnaud}

Le parti normand choisi par nos deux évêques leur permit une ascension sociale qui accompagna l'extraordinaire expansion de la monarchie anglo-normande de la seconde moitié du XI ${ }^{\mathrm{e}}$ siècle. L'évêque Arnaud qui devait posséder des biens, si on considère ses dons faits à Saint Vincent, semble présenter les traits d'un caractère intéressé. Quelques anecdotes prouvent, ici et là, que ses familiers connaissaient sa faiblesse pour l'argent et savaient en user. Les historiens de l'abbaye de Marmoutier qui eut à souffrir du traitement d'Arnaud ne manquèrent pas de souligner cet aspect de son personnage. Dom Martène, par exemple, fait état de l'animosité persistante de l'évêque Arnaud à l'égard de l'abbaye ${ }^{131}$. En 1067-1068, l'abbé Barthélémy écrit à Arnaud une longue lettre pour se plaindre de ce qu'il voulait injustement lui enlever des droits d'autel que l'évêque Vulgrin lui avait donnés pour son prieuré de Vivoin et demande justice, en menaçant de quitter leur union fraternelle avec l'église Saint-Julien du Mans ${ }^{132}$. D'après Mabillon, ces raisons n'émeuvent pas Arnaud, et Barthélemy doit ajouter à cette lettre des présents pour faire fléchir l'évêque ${ }^{133}$. L'abbé se plaint aussi de ce que l'évêque ait exigé 20 livres de deniers en échange d'une confirmation de biens en $1068^{134}$. Lorsque Arnaud vient à Avenières, prieuré de Notre-Dame du Ronceray, pour confirmer une remise de coutumes, il reçoit volontiers un cheval de la part des moniales ${ }^{135}$. Par ailleurs, les Actus nous font connaître les cadeaux que le roi Guillaume lui donna lors de son voyage en Angleterre, en 1069, pour les services rendus ${ }^{136}$. Si on considère seulement les legs qu'il fit à la cathédrale et aux chanoines de Saint-Julien, lors de son décès, Arnaud laissait tout de même quelques biens fonciers, des objets liturgiques en argent et un marc d'or ${ }^{137}$.

130. L'évêque du Mans Guy d'Étampes (1126-1135), remplaçant de Hildebert de Lavardin nommé à l'archevêché de Tours, peut-être d'origine anglaise, sera un évêque d'Henry I Beauclerc.

131. LEMESLE, Bruno, La société aristocratique..., op. cit., p. 102-104. Le pouvoir normand impliquait naturellement cette hostilité.

132. LaURAIN, Ernest, Cartulaire manceau..., op. cit., t. II, Vivoin, nº 5, p. 363-364.

133. MABILlon, Jean, ASOSB, saecul. VI, Benedict., Pars II, p. 388.

134. MARTEne, Edmond (éd.), "Histoire de l'abbaye de Marmoutier par l'abbé C. Chevalier ", Mémoires de la société archéologique de Touraine, Tome XXIV, p. 383 : "Barthélémy par reconnaissance lui donna 20 livres de deniers, payant bien grassement la gratification de cet évêque qui parut en cela avoir l'âme basse; aussi était-il d'une naissance assez obscure de Basse-Normandie dans le territoire d'Avranches. "

135. MARCHEGAY, Paul, Cartularium monasterii..., op. cit., Acte CCCLXV.

136. Actus, p. 377.

137. Busson, Gustave et LEDRU, Ambroise, Necrologe-Obituaire de la cathédrale du Mans, Archives historiques du Maine, t. VII, Le Mans, 1906, p. 317. Arnaud a également donné 
On peut se faire une idée de son réseau de relations en considérant, par exemple, les voyages qu'il accomplit en dehors de son diocèse. Arnaud ne fit que deux ou trois voyages extérieurs au royaume de France. Deux déplacements furent " politiques" : pendant la révolte de 1069, il s'embarqua pour l'Angleterre où le roi Guillaume se plut à le recevoir ${ }^{138}$ et en 1077 , où il rejoignit à l'abbaye du Bec le milieu épiscopal normand rassemblé autour de Lanfranc ${ }^{139}$. En février 1056, le scholasticus Arnaud se trouvait au concile de Chalon-sur-Saône avec son évêque Vulgrin ${ }^{140}$. Il participe également au grand concile de Poitiers, du 15 janvier $1078^{141}$. Enfin, Arnaud fit un ou deux voyages à Rome, en 1071 et/ou en $1074{ }^{142}$. Ce voyage fut mouvementé à l'aller comme au retour : Arnaud (il a une soixantaine d'années) et l'archevêque de Tours qu'il accompagnait furent attaqués et dévalisés à l'aller ${ }^{143}$. Puis laissant l'archevêque Raoul à Rome, Arnaud tomba, au retour, entre les mains d'Azzon, marquis d'Este, qui par ressentiment au souvenir des événements malheureux de 1069-1070 qui avaient entouré son fils Hugues, au Mans, le retint sept mois prisonnier. Arnaud s'en tira à bon compte puisqu'il fut libéré et comblé de cadeaux ${ }^{144}$.

\section{Hoёl}

Le personnage d'Hoël a plus de relief. Son action politique fut moindre mais son rôle religieux plus actif. Il eut la chance de pouvoir participer à des événements allant bien au-delà de l'ordinaire d'un simple diocèse. Sans négliger cette gestion quotidienne, Hoël fut associé à l'expansion politique du monde anglo-normand en même temps qu'il participa à sa mesure au développement de la réforme dite " grégorienne " dans tout l'ouest du royaume de France. Il fut ainsi amené à rencontrer les plus hautes personnalités politiques et religieuses de son temps.

La description que le biographe et ami d'Hoël fit de sa mort en fait un tableau édifiant, théatralisant la mort d'un prélat exemplaire. C'est le " modèle " épiscopal idéal. L'évêque, mis en scène sur son lit de mort, accueille les principaux membres de son Église et les clercs qui furent à son service. Préoccupation matérielle : distribution de ses biens à tous et aux pauvres, jusqu'à sa chemise et ses souliers (il ne garde pas même une

sa chasuble épiscopale enrichie d'orfrois qui servit longtemps après sa mort, aux jours de fête Actus, p. 381.

138. Actus, p. 377. On en profita pour saccager ses maisons et ses terres.

139. Cf. supra, note 48.

140. Cf. supra, note 29.

141. PonTAL, Odette, Les conciles..., op. cit., p. 181.

142. Cartulaire de Saint-Vincent, Acte 29. Le voyage y est nettement daté de 1071. Mais l'acte du Cartulaire manceau de Marmoutier, Sablé VIII, p. 78-79, où Renaud de Sablé évoque ce voyage est daté par Ernest Laurain de 1068-1084. La raison du voyage en est la demande faite par Rome à l'archevêque Raoul de Langeais de venir se justifier des accusations de simonie. Or ce problème est évoqué lors du concile de Carême 1074.

143. LaURAin, Ernest, Cartulaire manceau..., op. cit., Titres Généraux, p. 6.

144. Actus, p. 380. 
serviette pour s'essuyer les mains) ${ }^{145}$, dons au Chapitre de son Église ${ }^{146}$. Préoccupation spirituelle surtout : prières et pardon, levée d'excommunication pour ceux qui l'ont offensé, baiser de paix à chacun, dernier sacrement ${ }^{147}$. Ce tableau ne nous laisse guère entrevoir la fortune réelle de l'évêque Hoël. Il semble qu'il fut réellement un évêque exemplaire même si son portrait se veut ici édifiant. Il reste que l'évêque dut vivre sur un grand pied, comme il appartenait alors à la dignité de sa fonction et plus particulièrement à ce monde privilégié qu'était alors le monde ecclésiastique normand. Sa maison composée autant de clercs que de laïcs était nombreuse; la grâce de son hospitalité envers tous les religieux et particulièrement les moines était unique. Si son biographe a soin de préciser qu'il ne se départissait pas pour autant de sa sagesse et de sa piété ${ }^{148}$, la magnificence devait malgré tout lui plaire ${ }^{149}$.

Jusqu'en 1092, l'évêque Hoël fut essentiellement préoccupé de la défense des intérêts normands. Une des dernières manifestations où il paraît avec ses pairs d'Angleterre se situe le 27 janvier 1091 lorsque le roi Guillaume le Roux se trouve à Douvres, accompagné des plus grands magnats anglais, prêt à traverser la Manche ${ }^{150}$. Lorsque Hélie de La Flèche devient comte du Maine, l'évêque Hoël cesse d'être un Normand pour ne plus être qu'un évêque. Il ne se consacre plus en effet qu'à sa charge épiscopale au moment où précisément l'Église, celle du Mans, celle de Rome va le solliciter davantage.

Durant son épiscopat Hoël poursuivit activement les travaux de la cathédrale commencés par ses prédécesseurs. Le chœur, déjà construit sous Arnaud, fut pavé, décoré d'une voûte et de magnifiques vitraux. On y plaça un siège épiscopal et de nouveaux autels, les colonnes et les plafonds reçurent différentes peintures et les murs furent blanchis ${ }^{151}$. Dès que le nouveau sanctuaire fut prêt, Hoël organisa sa consécration, accompagnée de la translation des reliques de saint Julien, en présence de tous les personnages importants de l'Église du Mans et alentour, du nouvel archevêque

\footnotetext{
145. Ibidem, p. 396.

146. Necrologe-Obituaire..., op. cit., p. 183 (29 juillet 1096) Il donna à l'église cathédrale des livres et plusieurs ornements liturgiques. Les chanoines avaient déjà reçu églises et terres. Il donna également vingt marcs d'argent pour refaire le retable de l'autel qu'il avait donné aux pauvres, pendant la famine.
}

147. Actus, p. 396.

148. Ibidem, p. 383.

149. Cartulaire de Saint-Vincent, 738. Un détail précise qu'en 1096, une investiture se fit au moyen du bâton pastoral doré du prélat. Était-ce une crosse d'or? L'évêque Hoël alors malade s'est retiré dans une chambre " in cubiculo ". C'est Hildebert qui le remplace pour témoigner. 150. Regesta Regum Anglo-Normannorum, n 315 (Douvres) 319 (Hastings) 326-359; FREEMAN, E. A., " The reign of William Rufus ", 1882, vol. II, p. 484-485. On compte l'archevêque d'York, douze évêques, treize abbés, une huitaine de barons, onze chapelains ainsi que l'évêque Geoffroy de Coutances.

151. Actus, p. 383 et p. 394. Les travaux reprirent après l'exil de l'évêque. Un acte du Cartulaire de Saint-Vincent, $\mathrm{n}^{\circ} 25$, nous montre l'évêque et des témoins présidant un accord dans le nouveau chœur de Saint-Julien. 
de Tours Raoul d'Orléans, au point que de mémoire d'homme, jamais Le Mans ne vit pareille multitude ${ }^{152}$. Cette translation des reliques de saint Julien fut même connue d'Yves de Chartres ${ }^{153}$. Hoël entretient manifestement les meilleurs rapports avec ses pairs. Estimé d'Yves de Chartres, il le fut également de l'archevêque Raoul de Langeais qu'il assistait de ses conseils et de son amitié ${ }^{154}$. Après la mort de Raoul, en 1086, comme c'était sa responsabilité, Hoël se chargea du diocèse de Tours si malmené par les désordres récents ${ }^{155}$.

Complètement engagé dans la réforme de l'Église alors en pleine action, Hoël participa à de multiples conciles dispersés géographiquement : peutêtre présent aux trois conciles de Brioude, Autun et Dol en $1085^{156}$, il était en tout cas à saint-Florent de Saumur en 1094, lorsque Hugues de Die leva l'excommunication fulminée contre le comte Foulque le Rechin ${ }^{157}$. Quatre mois plus tard, il est à Autun (16 octobre 1094) où le même Hugues de Die, assisté de plus de trente évêques et plusieurs abbés, excommunia le roi Philippe pour avoir épousé Bertrade de Montfort du vivant de sa femme Berthe de Hollande ${ }^{158}$. Ce même concile aurait essayé une fois encore, de réconcilier les moines de Marmoutier avec l'archevêque Raoul. Peine perdue, puisqu'on retrouve les mêmes protagonistes pour les mêmes raisons à un colloque à Dol, vers 1094 ou 1095, avec cette fois Hugues de Die, Amat, archevêque de Bordeaux et l'archevêque Raoul. Hoël part alors pour l'Italie et accompagné par son nouvel archidiacre Hildebert, passe par Cluny où ils rencontrent l'abbé Hugues ${ }^{159}$. La fin de l'épiscopat d'Hoël fut une sorte de consécration : il eut la chance de rencontrer, de suivre et même de recevoir personnellement le pape Urbain II en sa propre demeure. De Cluny, Hoël put rejoindre Plaisance en Lombardie, où le pape tint concile vers la mi-carême ( ${ }^{\mathrm{er}}$ mars) $1095^{160}$. L'évêque retrouva le pape lors du fameux concile de Clermont qui s'ouvrit le 18 novembre $1095^{161}$. Après l'étape

152. Actus, p. 394, date exceptionnellement cet événement du 17 octobre 1093. Augustin FuICHE, Le règne de Philippe $I^{e r}$, p. 51, a rétabli justement la date de cette translation au 17 octobre 1092.

153. Jean LECLERQ, op. cit., Lettre 21. Yves de Chartres remercie Hoël pour ses prières qui ont aidé à sa libération.

154. Actus, p. 384.

155. Ibidem.

156. PONTAL, Odette, Les conciles..., op. cit., p. 187, montre que ces conciles parfois placés en 1094 se tinrent avant la mort du pape Victor III (1087) sous l'épiscopat de l'archevêque Raoul (1073-1086) qui assista aux trois conciles.

157. Gallia Christiana, t. IV, Instrumenta, col. 10.

158. PonTAL, Odette, Les conciles..., op. cit., p. 223.

159. Cf. supra note 72. Soc. Bolland, Acta Sanctorum, XXIX, aprilis III, "Vita S. Hugonis ab. Cluniac. Auctore Hildeberto episcopo Cenomanensi ", col. 639. L'HuILliER, Albert, Saint Hugues, abbé de Cluny, Solesmes, 1888, p. 381.

160. HeFELE, Charles-Joseph et LECLERCQ, Henri, Histoire des conciles, Paris, 1912, t. V, Livre XXXII, p. 388-396.

161. Ibidem, p. 399. CROzET, René, « Le voyage d'Urbain II et ses négociations avec le clergé de France ", Revue Historique, 1937, p. 284 : " Des diocèses de la Loire moyenne, étaient venus Hoël, évêque du Mans qui avait assisté au concile de Plaisance, et des personnages 
d'Angers, le 10 février 1096, l'évêque reçut le pape au Mans in domo sua, avec tout le faste possible, pour un séjour qui dura du 16 au 18 février $1096^{162}$. Le pape y confirma un certain nombre de droits en faveur de SaintPierre-de-la-Cour ${ }^{163}$. Ce fut un des derniers actes importants de la vie publique d'Hoël puisqu'il mourut seulement quatre mois plus tard, le 29 juillet 1096, d'une maladie contractée récemment, à l'âge de cinquante ans environ ${ }^{164}$.

Si de façon générale, le choix des évêques ne cesse d'être politique, les nominations d'Arnaud et Hoël se sont révélées efficaces. L'évêché du Mans, éminemment stratégique mais particulièrement malaisé et difficile, leur fut confié pour qu'ils le maintiennent et si possible le consolident dans les mains des Normands. Leur mission fut aussi de placer à des postes clefs, non pas des membres de leur famille - ils n'en avaient pas - mais des soutiens de la dynastie normande. Ils eurent donc à composer, à un moment sensible de l'histoire de l'Église, avec tous les acteurs de leur entourage, les puissances politiques, mais aussi les puissances religieuses dont ils dépendaient. Ils furent choisis pour être des hommes d'action et de compromis et se rapprochent en cela de leurs contemporains anglo-normands.

Arnaud et Hoël ne font pas partie de cette aristocratie féodale dont le souci essentiel est la défense de son patrimoine lignager et dont les préoccupations tournent autour de ses stratégies familiales. Évêques normands, ils ne ressemblent pas à leurs pairs de Normandie, n'étant ni des membres proches, ni même lointains de la famille du duc ou de l'aristocratie comme leurs contemporains Odon de Conteville, Geoffroy de Montbray ou Hugues d'Eu. S'ils sont issus, du moins pour Hoël, de la Kofkapelle sur laquelle Michel Parisse en écho à Bernard Guillemain attirait l'attention, ils ne semblent pas non plus être comparables à leurs homologues lorrains qui sont jeunes, d'origine noble et très instruits. Contemporains de Lanfranc du Bec et d'Anselme de Canterbury, ils ne vont pas chercher à approfondir ou à exploiter leurs connaissances et aucun d'eux n'a laissé de correspondance suivie, ni même quelque écrit. Ils sont sans famille, sans véritable parenté ou lignage et, contrairement à certains de leurs semblables normands, ils n'eurent pas de descendance, ni même de patrimoine foncier. Ils n'ont pas de domaine familial et aucune alliance parentale ne les relie à un quelconque fief. Les ambitions du fondateur de l'école épiscopale Robert le Grammairien semblent s'être limitées à transmettre une tradition intellectuelle à son neveu Arnaud et l'ébauche d'une

de premier plan tels qu'Yves, évêque de Chartres et Geoffroy, abbé de Vendôme. " On peut y joindre Raoul archevêque de Tours, Bernard de Saint-Venant, abbé de Marmoutier, Baudry de Bourgueil, le futur historien de la croisade.

162. Actus, p. 395. Rien n'a manqué à l'illustre visiteur et aux gens de sa suite, malgré les rigueurs d'une année de disette.

163. Menjot d’Elbenne, Victe Samuel et Denis, Abbé L.-J., Cartulaire du chapitre royal de Saint-Pierre-de-la-Cour, Le Mans, 1093-1907, t. II, Acte 11.

164. Actus, p. 396. 
dynastie cléricale qui aurait été établie entre l'oncle, le neveu, puis le proche disciple tourna rapidement court. Leur seule famille fut d'appartenir à la fois à l'entourage du roi, ce qui assurait leur docilité et à la hiérarchie de l'église séculière ce qui leur assurait une certaine aisance sociale. Hors norme par conséquent, ces homines novi sont vraiment les hommes du roi Guillaume et du parti normand, agissant en marge du duché de Normandie et du royaume d'Angleterre, veillant toujours sur cet évêché récemment conquis. Leur mission politique fut cependant à terme un échec puisque le comté du Maine cessa d'être normand durant l'épiscopat même d'Hoël et qu'après sa mort l'évêché passa aux mains d'un Vendômois, Hildebert de Lavardin plutôt proche du nouveau comte du Maine Hélie de La Flèche et que le roi d'Angleterre Guillaume le Roux persécuta en vain. Mais cet échec ne fut pas le sien.

Relativement lettrés, ces prélats étaient parfaitement conscients de leur rôle et de leur dignité. Ils ne ressemblent en rien aux évêques batailleurs et "féodaux " du début du siècle. Ils se sentirent impliqués dans la réforme de l'Église : si la situation politique difficile et l'âge ne laissèrent sans doute pas à Arnaud la possibilité de suivre véritablement le modèle de l'évêque grégorien, il revint à Hoël et à sa génération de s'en rapprocher davantage. L'un comme l'autre surent, malgré le contexte politique difficile, assurer une dignité à leur fonction d'homme d'église : ils respectèrent notamment la règle de célibat prôné alors par Rome.

Ce ne fut pas le moindre des mérites du roi Guillaume le Conquérant d'avoir su choisir non seulement de bons serviteurs, mais aussi de bons évêques. 


\section{RESUME}

Après sa fragile conquête du comté du Maine en 1063, le duc de Normandie Guillaume devait absolument contrôler l'évêché du Mans face à l'Anjou conquérant et à l'aristocratie mancelle, elle-même encline à retrouver son indépendance.

Le choix du duc, devenu roi d'Angleterre en 1066, se porta sur deux clercs, Arnaud et Hoël, dont les épiscopats caractérisèrent l'occupation normande du comté, de 1065 à 1096.

Arnaud et Hoël, issu sans doute d'une même famille cléricale avranchine, sont des " homines novi ", parfaitement dévoués, formés à l'école épiscopale du Mans et pour Hoël, à la propre chapelle du roi. Ils témoignent d'une nouvelle génération épiscopale en phase avec la réforme de l'Église alors en marche, notamment dans l'Ouest de la France. Mais ils sont surtout les agents du duc roi, appliquant strictement sa politique en favorisant, notamment au sein même de l'Église séculière et régulière mancelle, la constitution de réseaux de fidélités issus directement des alliés et familiers du roi, implantés en terres proches.

\section{ABSTRACT}

Following his frail conquest of the County of Maine in 1063 and faced by both threatening Anjou and the lords of Le Mans trying to regain their independence, William, Duke of Normandy, absolutely needed to gain control of the See of Le Mans.

The Duke, having become King og England in 1066, successively turned to two clerks, Arnaud and Hoël, who were the symbol of the Norman overlordship of the county from 1065 to 1096.

Arnaud and Höel, who most likely came from the same "avranchine" clerical family are "homines novi" and were in all probality educated at the cathedral school of Le Mans and in particular Hoël's case, at the king's own chapel.

They belong to this new bishop generation involved in the Reformation of Church that was very active in the Western parts of France.

But they are mostly William's agents favoring, within the secular and regular "mancelle" church, the creation of networks of loyalty coming directly from the King's allies, friends and kins, seeded in close by lands. 
